\title{
Profiling the proteomics in honeybee worker brains submitted to the proboscis extension reflex
}

\author{
Anally Ribeiro da Silva Menegasso ${ }^{a}$, Marcel Pratavieira ${ }^{a}$, Juliana de Saldanha da Gama Fischer ${ }^{\text {b }}$, \\ Paulo Costa Carvalho ${ }^{\mathrm{b}}$, Thaisa Cristina Roat ${ }^{\mathrm{a}}$, Osmar Malaspina ${ }^{\mathrm{a}}$, Mario Sergio Palma ${ }^{\mathrm{a}, *}$ \\ a Center of the Study of Social Insects, Department of Biology, Institute of Biosciences of Rio Claro, São Paulo State University (UNESP), Rio Claro, SP 13500, Brazil \\ b Laboratory for Proteomics and Protein Engineering, Carlos Chagas Institute, Fiocruz, Paraná, Brazil
}

\section{A R T I C L E I N F O}

\section{Article history:}

Received 13 January 2016

Received in revised form 20 May 2016

Accepted 25 May 2016

Available online 31 May 2016

\section{Keywords:}

Neuroproteomics

Shotgun

Label-free quantitation

Honeybee

Memory

\begin{abstract}
A B S T R A C T
The proboscis extension reflex (PER) is an unconditioned stimulus (US) widely used to access the ability of honeybees to correlate it with a conditioned stimulus (CS) during learning and memory acquisition. However, little is known about the biochemical/genetic changes in worker honeybee brains induced by the PER alone. The present investigation profiled the proteomic complement associated with the PER to further the understanding of the major molecular transformations in the honeybee brain during the execution of a US. In the present study, a quantitative shotgun proteomic approach was employed to assign the proteomic complement of the honeybee brain. The results were analyzed under the view of protein networking for different processes involved in PER behavior. In the brains of PER-stimulated individuals, the metabolism of cyclic/heterocyclic/aromatic compounds was activated in parallel with the metabolism of nitrogenated compounds, followed by the up-regulation of carbohydrate metabolism, the proteins involved with the anatomic and cytoskeleton; the down-regulation of the anatomic development and cell differentiation in other neurons also occurred.

Significance: The assay of proboscis extension reflex is frequently used to access honeybees' ability to correlate an unconditioned stimulus with a conditioned stimulus (such as an odor) to establish learning and memory acquisition. The reflex behavior of proboscis extension was associated with various conditioned stimuli, and the biochemical/genetic evaluation of the changes occurring in honeybee brains under these conditions reflect the synergistic effects of both insect manipulations (training to answer to an unconditioned stimulus and training to respond to a conditioned stimulus). Little or no information is available regarding the biochemical changes stimulated by an unconditioned stimulus alone, such as the proboscis extension reflex. The present investigation characterizes the proteomic changes occurring in the brains of honeybee workers submitted to proboscis extension reflex. A series of metabolic and cellular processes were identified to be related to the reflex of an unconditioned stimulus. This strategy may be reproduced to further understand the processes of learning and memory acquisition in honeybees.
\end{abstract}

(C) 2016 Elsevier B.V. All rights reserved.

\section{Introduction}

Despite a small brain size, honeybees have been used as important models in neurobiology; these insects exhibit a wide repertoire of behaviors and a remarkable ability to learn [1]. Honeybees can identify odors and colors [2], as well the shapes and the relationships between objects such as sameness/differences [3,4], the order of the objects [5], numerical attributes associated with the objects [6], and relative positioning above/bellow [7]. According to Zhang et al. (2006) [8] and Pahl et al. (2007) [9], these insects can learn and make decisions regarding

\footnotetext{
* Corresponding author at: CEIS-IBRC- UNESP, Av. 24 A, no. 1515, Bela Vista, - Rio Claro, SP CEP 13506-900, Brazil.

E-mail address: mspalma@rc.unesp.br (M.S. Palma).
}

where/when to go within a temporal scale; they even have the ability to associate elements of the circadian cycle.

Their outstanding olfactory memory is important in the search for food and may be developed in association with a series of various clues that are important in foraging $[10,11]$. These abilities appear to be important in ensuring that worker bees develop navigational routes, establish landmarks for these routes, and identify their forage sources $[1,12,13]$.

The proboscis extension reflex (PER) represents an experimental strategy to assess honeybees' ability to exhibit an unconditioned stimulus (US) [14]. This behavior represents an effective paradigm for analyzing the physiology and psychological rules underlying the behavioral repertoire of these insects [15]. Notably, PER is an aspect of honeybee feeding behavior; when the antenna is stimulated by contact with a solution of carbohydrates, the insects automatically extend their proboscis 
to drink the sugars solution, thereby constituting a reflex response to a US [16,17]. Honeybees acquire/develop an olfactory memory from the food source during visits to flowers for collecting nectar and transfer this memory to the paradigm in the laboratory during experiments [17]. The PER paradigm is frequently used to investigate learning and memory in honeybees, especially in evaluating associative learning between US and different types of CS, such as exhibiting PER each time that an identified odor is associated with a reward offered to the bees (such as drinking a solution of carbohydrates), a classic method of Pavlovian conditioning [18].

The molecular mechanisms of olfactory learning and memory in honeybees have been thoroughly investigated to improve understanding at the biochemical and physiological levels. Thus, a correlation between a reduced level of expression of protein kinase A and $\mathrm{N}$-methyl$\mathrm{D}$-aspartate receptors and the impairment of the long-term memory of workers of Apis mellifera was found [19,20]. Other studies also reported the involvement of various protein types in learning and memory acquisition in the honeybee brain; thus, the expression levels of the receptors for acetylcholine, octopamine, dopamine, and glutamate [21,22,23,24] and calcium/calmodulin-dependent kinase II [25] are correlated with the abovementioned processes. Honeybees submitted to training for olfactory memory presented the down-regulation of many protein-coding genes [26,27]. A similar conclusion was also reported in a study of differentially expressed mRNA in honeybees after maze learning assays [28]. Hadar and Menzel (2010) [29] demonstrated that excitatory and inhibitory learning occur through different molecular circuits and that the blocking of protein synthesis inhibited the consolidation of the excitatory learning, indicating that this process is directly dependent on the synthesis of proteins in the honeybee brain.

Despite the large number of studies related to the learning and memory acquisition using PER as an experimental strategy to assess the honeybees' ability to exhibit a US, very few studies have examined the genetic, biochemical, and physiological processes demanded by the PER alone. The studies generally focus on the effects of a PER associated with a CS; therefore, even the major biochemical processes involved with this reflex behavior are unknown. Thus, the main objective of the present investigation is to profile the proteomic complement associated with PER, to further understand the major molecular transformations occurring in the honeybee brain during the execution of a US. In the present study, a shotgun approach combined with a label-free strategy for protein quantification was applied to determine the proteomic complement of the honeybee brain. The results were analyzed in light of the proteins networking for different processes involved with PER reflex behavior.

\section{Experimental section}

\subsection{Materials}

A Qubit ${ }^{\circledR}$ Protein Assay Kit and RapiGest SF acid-labile surfactant were purchased from Invitrogen (Carlsbad, CA) and Waters Corp. (Milford, MA), respectively. The sequencing-grade modified trypsin was purchased from Promega (San Luis Obispo, CA, USA). All other laboratory reagents were acquired from Sigma-Aldrich (St. Louis, MO).

\subsection{PER test}

Honeybees (A. mellifera) were maintained in the apiary of the Bioscience Institute of the University of Sao Paulo State, Campus of Rio Claro, SP, Brazil. The colony used in the experiments was well formed, free of disease, well fed, and in possession of a laying queen. Initially, a honeycomb containing larvae (free of bees) was collected from the colony and maintained for $24 \mathrm{~h}$ inside a Biochemical Oxygen Demand incubator (ELECTROlab) previously set to $32{ }^{\circ} \mathrm{C}$ and $70 \%$ relative humidity. Newly emerged workers were marked (day 0 ) on the thorax using a nontoxic paint and returned to the colony for later capture when they reached 20 days of age.

The behavior of "Proboscis Extension Reflex" (PER) was used as an input reference for neuroproteomic studies. PER is the proboscis extension by an insect as a reflex to antennal stimulation. Individual bees were securely attached to the tube with small pieces of tape to restrain the bees without harming them. Their heads protruded from the tube, and only the antennae and mouthparts could move freely. Then, each bee was subjected to sucrose odor (PER group). Each trial involved one stimulation with sucrose solution and one stimulation with water with an interval of 1 min between the stimulations; the interval between one trial and another was $5 \mathrm{~min}$. The bees were submitted to a total of five trials.

The PER group was composed of individuals that responded to stimuli with sucrose $(80 \% \mathrm{v} / \mathrm{v})$ but did not respond to water in any of the trials, and the control group was submitted to the same conditions applied to the PER group, with the exception of not exposing the insects to the sucrose odor. After collection, the bees were immediately frozen in liquid nitrogen where they remained until the head was dissected in a cocktail of protease inhibitor for sample preparation.

\subsection{Sample preparation and in-solution digestion}

Proteins were extracted using RapiGest surfactant ( $0.2 \%$ final) and macerated for $5 \mathrm{~min}$. Subsequently, the samples were centrifuged for $15 \mathrm{~min}$ at $20,000 \times g$ to remove insoluble material. Afterwards, the total protein concentration was determined with the Qubit ${ }^{\circledR}$ Protein Assay Kit together with the Qubit $₫ 3.0$ fluorometer according to the manufacturer's instructions. Two hundred micrograms of proteins were reduced with $10 \mathrm{mM}$ (final) of dithiothreitol for $30 \mathrm{~min}$ at $60{ }^{\circ} \mathrm{C}$ and, after cooled to room temperature, the proteins were alkylated with $30 \mathrm{mM}$ (final) of iodoacetamide for an additional $35 \mathrm{~min}$ at room temperature. Finally, the proteins were digested with sequencinggrade modified trypsin added at an enzyme/substrate ratio of 1:50 $(\mathrm{w} / \mathrm{w})$. The digestion was performed for $18 \mathrm{~h}$ at $37^{\circ} \mathrm{C}$. The reaction was stopped with trifluoeacetic acid to a final concentration of $0.4 \%$ and incubated at $37^{\circ} \mathrm{C}$ for an additional $40 \mathrm{~min}$ to enhance the hydrolysis of RapiGest. Subsequently, the sample was centrifuged for $10 \mathrm{~min}$ at $20,000 \times \mathrm{g}$ at $4{ }^{\circ} \mathrm{C}$ to remove insoluble material. The digested peptide mixture was equally divided into three aliquots of $10 \mu \mathrm{g}$, which were individually desalted over stage tip in-house columns that were packed with SPE disks $\left(\mathrm{C}_{18}, 47 \mathrm{~mm}\right)$ and dried in a vacuum.

\subsection{LC-MS/MS acquisition}

The samples were subjected to LC-MS/MS analysis with a Thermo Scientific Easy-nLC 1000 ultra-high-performance liquid chromatography (UPLC) system coupled with a LTQ-Orbitrap XL ETD mass spectrometer (Mass Spectrometry Facility-RPT02H PDTIS/Carlos Chagas Institute-Fiocruz Paraná), as follows. The peptide mixtures were loaded onto a column (75 $\mu \mathrm{m}$ i.d., $15 \mathrm{~cm}$ long) packed in-house with a $3.2 \mu \mathrm{m}$ ReproSil-Pur $\mathrm{C}_{18}$-AQ resin (Dr. Maisch) with a flow of $500 \mathrm{~nL} / \mathrm{min}$ and subsequently eluted with a flow of $250 \mathrm{~nL} / \mathrm{min}$ from $5 \%$ to $40 \% \mathrm{ACN}$ in $0.5 \%(\mathrm{v} / \mathrm{v})$ formic acid and $0.5 \%(\mathrm{v} / \mathrm{v})$ DMSO in a $120 \mathrm{~min}$ gradient [30]. The mass spectrometer was set in a data-dependent mode to automatically switch between MS and MS/MS ( $\mathrm{MS}_{2}$ ) acquisition. Survey fullscan MS spectra (from $m / z$ 300-2000) were acquired in the Orbitrap analyzer with the resolution $R=60,000$ at $\mathrm{m} / z 400$ (after accumulation to a target value of $1,000,000$ in the linear trap). The ten most intense ions were sequentially isolated and fragmented in the linear ion trap using collisional induced dissociation at a target value of 10,000. Previous target ions selected for MS/MS were dynamically excluded for $90 \mathrm{~s}$. The total cycle time was approximately $3 \mathrm{~s}$. The general mass spectrometric conditions were spray voltage, $2.4 \mathrm{kV}$; no sheath and auxiliary gas flow; ion transfer tube temperature $175^{\circ} \mathrm{C}$; collision gas pressure, $1.3 \mathrm{mTorr}$; normalized energy collision energy using wide-band activation mode; 


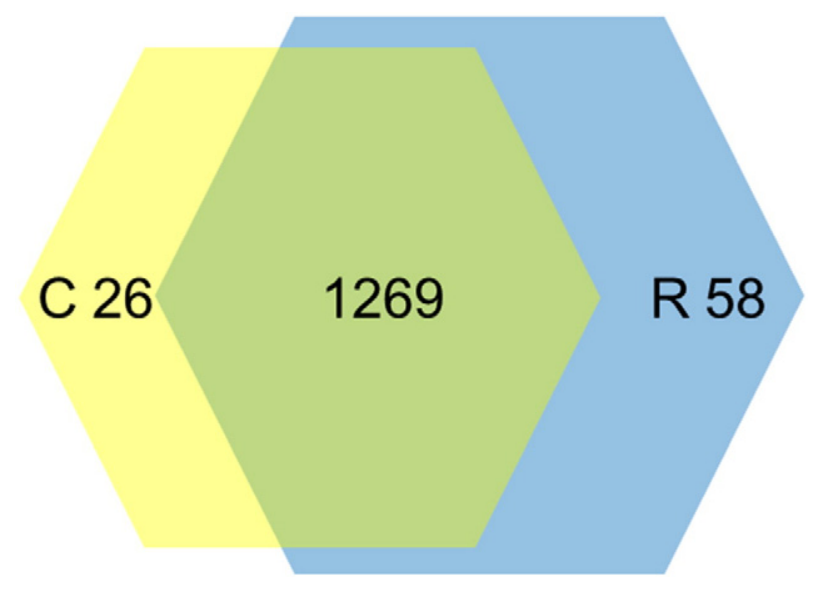

Fig. 1. Venn Diagram of identified proteins. C-number of proteins uniquely identified in the control group; R-number of proteins uniquely identified in the PER group.

$35 \%$ for $\mathrm{MS}_{2}$. The ion selection threshold was 250 counts for $\mathrm{MS}_{2}$. An activation $\mathrm{q}=0.25$ and activation time of $30 \mathrm{~ms}$ were applied in $\mathrm{MS}_{2}$ acquisitions. Technical replicates were performed with and without multistage activation.

\subsection{Mass spectrometry data analysis}

The reference proteome set of Apis, composed of 72,781 sequences, was downloaded from the NCBI (http://www.ncbi.nlm.nih.gov/) on February 06, 2015. PatternLab v3.2 [31] was used for generating a target-decoy database by grouping subset sequences, adding the sequences of 127 common mass spectrometry contaminants, and, for each sequence, including a reversed version of it. The search was performed using PatternLab's integrated Comet [32] search engine. Briefly, the search parameters included fully tryptic and semi-tryptic peptide candidates with masses between 600 and $6000 \mathrm{Da}$. The modifications were the carbamidomethylation of cysteine and the oxidation of methionine as fixed and variable, respectively. The precursor tolerance was $40 \mathrm{ppm}$, and we used bins of $1.0005 \mathrm{Da}$ for analyzing the fragment ion scans. The validity of the peptide sequence matches (PSM) was assessed using PatternLab's Search Engine Processor module (SEPro) [33]. Briefly, identifications were grouped by charge state $(+2$ and $\geq+3)$ and then by tryptic status (tryptic and semi-tryptic), resulting in four distinct subgroups. For each group, Comet's XCorr, DeltaCN, and Secondary score values were used to generate a Bayesian discriminating function. A cutoff score was established to accept a false discovery rate (FDR) of $1 \%$ based on the number of decoys. This procedure was independently performed on each data subset, resulting in a false-positive rate that was independent of tryptic status or charge state. Proteins identified with a single mass spectrum required the identification to have an XCorr greater than 2.5. A minimum sequence length of 6 amino acid residues was required. The results were post-processed to accept PSM with less than $7 \mathrm{ppm}$. The proteins were grouped according to maximum parsimony using the bipartite graph approach [34].

\subsection{Label-free quantitation}

A label-free protein quantitative analysis was performed according to the normalized spectral abundance factor (NSAF) [35] provided by Search Engine Processor (SEPro). Differentially abundant proteins were pinpointed using PatternLab's [Referencia] TFold Module [Referencia]. Briefly, the later relies on a theoretical FDR estimator (Benjamini-Hochberg [Referencia]) to maximize the number of identifications that satisfy both a fold-change cutoff that varies with the $t$-test $p$-value as a power law and a stringency criterion that aims to detect lowly abundant proteins that could yield false positives.
Table 1

Proteins identified uniquely in the control group. Results below listed only proteins obtained for $p$-values $<0.01$.

\begin{tabular}{ll}
\hline $\begin{array}{l}\text { Accession } \\
\text { code }\end{array}$ & Protein \\
\hline 572316394 & $\begin{array}{l}\text { Gephyrin-like isoform X1 [Apis } \\
\text { dorsata] }\end{array}$ \\
572309684 & $\begin{array}{l}\text { Cytochrome } c \text { oxidase subunit } \\
5 B, \text { mitochondrial-like [Apis } \\
\text { dorsata] }\end{array}$ \\
820861115 & $\begin{array}{l}\text { Cell cycle control protein 50A } \\
\text { isoform X1 [Apis florea] }\end{array}$ \\
572266110 & $\begin{array}{l}\text { Eukaryotic peptide chain release } \\
\text { factor subunit 1-like isoform X1 } \\
\text { [Apis dorsata] }\end{array}$ \\
820864455 & $\begin{array}{l}\text { E3 ubiquitin-protein ligase } \\
\text { SMURF2 isoform X1 [Apis florea] }\end{array}$ \\
& \\
520865977 & $\begin{array}{l}\text { Alpha- } N \text {-acetylglucosaminidase } \\
\text { [Apis florea] } \\
\text { Melittin }\end{array}$ \\
& $\begin{array}{l}\text { Microsomal triglyceride transfer } \\
\text { protein large subunit-like [Apis }\end{array}$ \\
572307601825 &
\end{tabular}

48101413 tRNA N6-adenosine threonylcarbamoyltransferase [Apis mellifera]

571572819 85/88 kDa calcium-independent phospholipase A2-like [Apis mellifera]

380021437 cGMP-dependent protein kinase, isozyme 2 forms cD5/T2 [Apis florea]

380017597 Putative ATP-dependent RNA helicase Pl10 [Apis florea]

571501059 Importin subunit alpha-3 [Apis mellifera]

380028389 Uncharacterized protein LOC100866826 [Apis florea]

820858777 Acetyl-CoA acetyltransferase, cytosolic [Apis florea]

66508242 Cysteine sulfinic acid decarboxylase-like isoform $\mathrm{X} 3$ [Apis mellifera]

820865075 Uncharacterized protein LOC100872391 [Apis florea]

572318265 Metaxin-2-like isoform X2 [Apis dorsata]

Function

Establishment of synaptic

specificity at neuromuscular junction

Mitochondrial electron transport: gene expression

Transport

Translation; gene expression; directs the termination of nascent peptide synthesis (translation) in response to the termination codons UAA, UAG, and UGA Gene expression; protein ubiquitination involved in ubiquitin-dependent protein catabolic process

Lipid transport

Carbohydrate metabolic process

It increases the permeability of cell membranes to ions, particularly $\mathrm{Na}+$ and indirectly $\mathrm{Ca} 2+$ tRNA processing

Lipid metabolic process; Fc-gamma receptor signaling pathway involved in phagocytosis Signal transduction; neuron migration

Translational initiation; cell differentiation Cytokine-mediated signaling pathway Unknown

Response to starvation; ketone body biosynthetic process; brain development

Carboxylic acid metabolic process; taurine biosynthetic process

Unknown

Protein targeting to mitochondrion

820838108 Type-2 histone deacetylase 1 [Apis florea]

110755983 Coiled-coil domain-containing protein 58-like [Apis mellifera]

571577446 Ubiquitin carboxyl-terminal hydrolase isoform X1 [Apis mellifera]

380013771 ATP-binding cassette subfamily E member 1 [Apis florea]

373203037 Dehydrogenase/reductase SDR family member 7 [Apis cerana]

572306641 DNA mismatch repair protein Mlh3-like [Apis dorsata]

571507718 nesprin-1-like [Apis mellifera]

572305886 Methionine-tRNA ligase, cytoplasmic-like [Apis dorsata]
Transcriptional regulation

Unknown

DNA repair; protein deubiquitination

May protect against heart failure under conditions of tachycardic stress; transport Oxidation-reduction process

Mismatch repair; protein localization

May be involved in the maintenance of nuclear organization and structural integrity

Gene expression; translation 
Table 2

Proteins identified uniquely in the PER group. Results below listed only proteins obtained for $p$-values $<0.01$.

\begin{tabular}{|c|c|c|}
\hline $\begin{array}{l}\text { Accession } \\
\text { code }\end{array}$ & Protein & Function \\
\hline 572303892 & $\begin{array}{l}\text { Tropomyosin-1, isoforms } 9 \\
\text { A/A/B-like isoform X34 [Apis } \\
\text { dorsata] }\end{array}$ & $\begin{array}{l}\text { Muscle contraction; dendrite } \\
\text { morphogenesis }\end{array}$ \\
\hline 20138953 & Full = Major royal jelly protein 3 & Nutrition \\
\hline 572308465 & $\begin{array}{l}\text { Troponin I-like isoform X21 [Apis } \\
\text { dorsata] }\end{array}$ & Muscle contraction \\
\hline 373211472 & $\begin{array}{l}40 \text { S ribosomal protein S23 [Apis } \\
\text { cerana] }\end{array}$ & Tanslation; gene expression \\
\hline 380030096 & $\begin{array}{l}60 S \text { ribosomal protein L37a [Apis } \\
\text { florea] }\end{array}$ & Translation; focal adhesion \\
\hline 572297073 & Protein FAM162B-like [Apis dorsata] & $\begin{array}{l}\text { Integral component of } \\
\text { membrane }\end{array}$ \\
\hline 328782283 & $\begin{array}{l}\text { Tumor suppressor candidate 3-like } \\
\text { [Apis mellifera] }\end{array}$ & $\begin{array}{l}\text { Protein } N \text {-linked } \\
\text { glycosylation; transport; } \\
\text { cognition }\end{array}$ \\
\hline 380014359 & $\begin{array}{l}\text { Scavenger receptor class B member } \\
1 \text { [Apis florea] }\end{array}$ & $\begin{array}{l}\text { Receptor-mediated } \\
\text { endocytosis; cell adhesion }\end{array}$ \\
\hline 380028021 & $\begin{array}{l}\text { Bifunctional purine biosynthesis } \\
\text { protein PURH [Apis florea] }\end{array}$ & $\begin{array}{l}\text { Purine biosynthesis; } \\
\text { brainstem development; } \\
\text { cerebral cortex development }\end{array}$ \\
\hline 328777128 & $\begin{array}{l}\text { Putative peptidyl-tRNA hydrolase } \\
\text { PTRHD1-like isoformX2 [Apis } \\
\text { mellifera] }\end{array}$ & $\begin{array}{l}\text { Aminoacyl-tRNA hydrolase } \\
\text { activity }\end{array}$ \\
\hline 571574382 & $\begin{array}{l}\text { Chymotrypsin inhibitor-like isoform } \\
\text { X3 [Apis mellifera] }\end{array}$ & Peptidase inhibitor activity \\
\hline 820848042 & $\begin{array}{l}\text { dnaJ homolog subfamily C member } \\
22 \text { [Apis florea] }\end{array}$ & Protein refolding \\
\hline 380015267 & $\begin{array}{l}\text { Persulfide dioxygenase ETHE1, } \\
\text { mitochondrial isoform X1 [Apis } \\
\text { florea] }\end{array}$ & $\begin{array}{l}\text { hydrogen sulfide catabolism } \\
\text { in the mitochondrial matrix; } \\
\text { glutathione metabolic } \\
\text { process. }\end{array}$ \\
\hline 380017778 & $\begin{array}{l}\text { Programmed cell death protein } 5 \\
\text { [Apis florea] }\end{array}$ & $\begin{array}{l}\text { Apoptotic process; cellular } \\
\text { response to transforming } \\
\text { growth factor beta stimulus; }\end{array}$ \\
\hline 571527764 & $\begin{array}{l}\text { Papilin-like isoform X2 [Apis } \\
\text { mellifera] }\end{array}$ & $\begin{array}{l}\text { Cell rearrangements; } \\
\text { modulating } \\
\text { metalloproteinases action } \\
\text { during organogenesis }\end{array}$ \\
\hline 571573872 & $\begin{array}{l}\text { Hydroxymethylglutaryl-CoA lyase, } \\
\text { mitochondrial-like isoform X1 [Apis } \\
\text { mellifera] }\end{array}$ & $\begin{array}{l}\text { Ketogenesis (alternative } \\
\text { source of energy to glucose); } \\
\text { mitochondrion organization }\end{array}$ \\
\hline 66514532 & $\begin{array}{l}\text { Guanine nucleotide-binding protein } \\
\text { subunit beta-2-like [Apis mellifera] }\end{array}$ & $\begin{array}{l}\text { Recruitment, assembly } \\
\text { and/or regulation of a variety } \\
\text { of signaling molecules }\end{array}$ \\
\hline 572314172 & $\begin{array}{l}\text { Nucleolar protein } 58 \text {-like isoform } \\
\text { X2 [Apis dorsata] }\end{array}$ & $\begin{array}{l}\text { rRNA modification; cell } \\
\text { growth }\end{array}$ \\
\hline 572271381 & $\begin{array}{l}\text { Putative ferric-chelate reductase } 1 \\
\text { homolog isoform X1 [Apis dorsata] }\end{array}$ & Oxidation-reduction process \\
\hline 820844091 & $\begin{array}{l}\text { Asparagine synthetase } \\
\text { [glutamine-hydrolyzing] isoform X1 } \\
\text { [Apis florea] }\end{array}$ & $\begin{array}{l}L \text {-asparagine biosynthesis; } \\
\text { response to nutrient levels }\end{array}$ \\
\hline 820866486 & $\begin{array}{l}\text { Small ubiquitin-related modifier } 3 \\
\text { [Apis florea] }\end{array}$ & $\begin{array}{l}\text { Nuclear transport, DNA } \\
\text { replication and repair, } \\
\text { mitosis and signal } \\
\text { transduction; } \\
\text { post-translational protein } \\
\text { modification }\end{array}$ \\
\hline 571576375 & $\begin{array}{l}\text { Long-chain fatty acid transport } \\
\text { protein } 4 \text { [Apis mellifera] }\end{array}$ & $\begin{array}{l}\text { Response to nutrient; } \\
\text { transmembrane transport }\end{array}$ \\
\hline 572317990 & $\begin{array}{l}\text { PX domain-containing protein } \\
\text { kinase-like protein-like isoform X1 } \\
\text { [Apis dorsata] }\end{array}$ & $\begin{array}{l}\text { Binds to and modulates brain } \\
\text { Na,K-ATPase subunits } \\
\text { ATP1B1 and ATP1B3 and may } \\
\text { thereby participate in the } \\
\text { regulation of electrical } \\
\text { excitability and synaptic } \\
\text { transmission. }\end{array}$ \\
\hline 572297844 & $\begin{array}{l}\text { GDP-Man:Man(3)GlcNAc(2)-PP-Dol } \\
\text { alpha-1,2-mannosyltransferase-like } \\
\text { [Apis dorsata] }\end{array}$ & $\begin{array}{l}\text { Biosynthetic process; } \\
\text { post-translational protein } \\
\text { modification }\end{array}$ \\
\hline 380024704 & $\begin{array}{l}\text { Dihydroorotate dehydrogenase } \\
\text { (quinone), mitochondrial [Apis } \\
\text { florea] }\end{array}$ & $\begin{array}{l}\text { Response to starvation; } \\
\text { oxidation-reduction process }\end{array}$ \\
\hline 820844631 & Small nuclear ribonucleoprotein Sm & Splicing of cellular \\
\hline
\end{tabular}

Table 2 (continued)

\begin{tabular}{|c|c|c|}
\hline $\begin{array}{l}\text { Accession } \\
\text { code }\end{array}$ & Protein & Function \\
\hline & D3 [Apis florea] & $\begin{array}{l}\text { pre-mRNAs; central nervous } \\
\text { system development; neuron } \\
\text { differentiation }\end{array}$ \\
\hline \multirow[t]{2}{*}{820839774} & NADH dehydrogenase [ubiquinone] & Transfer of electrons from \\
\hline & $\begin{array}{l}1 \text { beta subcomplex subunit } 7 \\
\text { isoform X2 [Apis florea] }\end{array}$ & $\begin{array}{l}\text { NADH to the respiratory } \\
\text { chain; respiratory electron } \\
\text { transport chain }\end{array}$ \\
\hline 373204224 & Septin-2 [Apis cerana] & $\begin{array}{l}\text { Cytokinesis; neurogenesis; } \\
\text { regulation of } L \text {-glutamate } \\
\text { transport }\end{array}$ \\
\hline 380014988 & Apolipophorins [Apis florea] & $\begin{array}{l}\text { Transport for various types of } \\
\text { lipids; Wnt signaling } \\
\text { pathway; transport }\end{array}$ \\
\hline 572298373 & Apolipophorins-like [Apis dorsata] & $\begin{array}{l}\text { Transport for various types of } \\
\text { lipids; Wnt signaling } \\
\text { pathway; transport }\end{array}$ \\
\hline 820841040 & Coatomer subunit beta [Apis florea] & $\begin{array}{l}\text { Mediate biosynthetic protein } \\
\text { transport from the ER, via the } \\
\text { Golgi up to the trans Golgi } \\
\text { network }\end{array}$ \\
\hline 380017696 & $\begin{array}{l}\text { Mitochondrial import receptor } \\
\text { subunit TOM } 40 \text { homolog 1-like } \\
\text { [Apis florea] }\end{array}$ & $\begin{array}{l}\text { Channel-forming protein } \\
\text { essential for import of } \\
\text { protein precursors into } \\
\text { mitochondria }\end{array}$ \\
\hline 380022501 & $\begin{array}{l}\text { Endocuticle structural glycoprotein } \\
\text { SgAbd-1-like [Apis florea] }\end{array}$ & $\begin{array}{l}\text { Structural constituent of } \\
\text { cuticle }\end{array}$ \\
\hline 380022594 & $\begin{array}{l}\text { Endocuticle structural glycoprotein } \\
\text { SgAbd-2-like isoform X1 [Apis } \\
\text { florea] }\end{array}$ & $\begin{array}{l}\text { Structural constituent of } \\
\text { cuticle }\end{array}$ \\
\hline 373208644 & $\begin{array}{l}\text { Protein lethal(2)essential for life } \\
\text { [Apis cerana] }\end{array}$ & $\begin{array}{l}\text { Protein lipidation; regulation } \\
\text { of translational initiation by } \\
\text { eIF2 alpha phosphorylation }\end{array}$ \\
\hline 571540960 & $\begin{array}{l}\text { Non-specific lipid-transfer } \\
\text { protein-like isoform X1 [Apis } \\
\text { mellifera] }\end{array}$ & $\begin{array}{l}\text { May play a role in regulating } \\
\text { steroidogenesis }\end{array}$ \\
\hline 571576907 & $\begin{array}{l}\text { 26S protease regulatory subunit } 7 \\
\text { [Apis mellifera] }\end{array}$ & $\begin{array}{l}\text { ATP-dependent degradation } \\
\text { of ubiquitinated proteins; } \\
\text { protein polyubiquitination }\end{array}$ \\
\hline 300593245 & $\begin{array}{l}\text { Unnamed protein product [Apis } \\
\text { mellifera] }\end{array}$ & Unknown \\
\hline 572305981 & $\begin{array}{l}\text { Mitochondrial import inner } \\
\text { membrane translocase subunit } \\
\text { Tim8-like [Apis dorsata] }\end{array}$ & $\begin{array}{l}\text { Import and insertion of some } \\
\text { multi-pass transmembrane } \\
\text { proteins into the } \\
\text { mitochondrial inner } \\
\text { membrane; nervous system } \\
\text { development; }\end{array}$ \\
\hline 380020436 & $\begin{array}{l}\text { Regucalcin-like isoform X2 [Apis } \\
\text { florea] }\end{array}$ & $\begin{array}{l}\text { Modulates } \mathrm{Ca}^{2+} \text { signaling, } \\
\text { and } \mathrm{Ca}^{2+} \text {-dependent cellular } \\
\text { processes and enzyme } \\
\text { activities }\end{array}$ \\
\hline 110758964 & Regucalcin-like [Apis mellifera] & $\begin{array}{l}\text { Modulates } \mathrm{Ca}^{2+} \text { signaling, } \\
\text { and } \mathrm{Ca}^{2+-} \text { dependent } \\
\text { cellular processes and } \\
\text { enzyme activities }\end{array}$ \\
\hline 572302484 & $\begin{array}{l}\text { Solute carrier family } 25 \text { member } \\
\text { 46-like [Apis dorsata] }\end{array}$ & Transport \\
\hline 572307192 & $\begin{array}{l}\text { Neuronal calcium sensor 2-like } \\
\text { isoform X3 [Apis dorsata] }\end{array}$ & $\begin{array}{l}\text { Neuronal calcium sensor, } \\
\text { regulator of G } \\
\text { protein-coupled receptor } \\
\text { phosphorylation in a calcium } \\
\text { dependent manner }\end{array}$ \\
\hline 571514423 & Twitchin [Apis mellifera] & $\begin{array}{l}\text { Regulator of muscle } \\
\text { contraction and relaxation; } \\
\text { protein phosphorylation }\end{array}$ \\
\hline 571506597 & Histone H1.2-like [Apis mellifera] & $\begin{array}{l}\text { Histones } \mathrm{H} 1 \text { are necessary for } \\
\text { the condensation of } \\
\text { nucleosome chains into } \\
\text { higher-order structures }\end{array}$ \\
\hline 572313551 & $\begin{array}{l}\text { Protein lethal(2)essential for } \\
\text { life-like [Apis dorsata] }\end{array}$ & $\begin{array}{l}\text { protein lipidation; regulation } \\
\text { of translational initiation by } \\
\text { eIF2 alpha phosphorylation }\end{array}$ \\
\hline 572304388 & $\begin{array}{l}\text { Probable small nuclear } \\
\text { ribonucleoprotein Sm D1-like [Apis } \\
\text { dorsata] }\end{array}$ & $\begin{array}{l}\text { Essential for pre-mRNA } \\
\text { splicing; mRNA processing }\end{array}$ \\
\hline 66523683 & Aspartate-tRNA ligase, cytoplasmic & Translation; tRNA \\
\hline
\end{tabular}


Table 2 (continued)

\begin{tabular}{|c|c|c|}
\hline $\begin{array}{l}\text { Accession } \\
\text { code }\end{array}$ & Protein & Function \\
\hline & [Apis mellifera] & $\begin{array}{l}\text { aminoacylation for protein } \\
\text { translation }\end{array}$ \\
\hline 380015451 & $\begin{array}{l}\text { Tetra-peptide repeat homeobox } \\
\text { protein 1-like [Apis florea] }\end{array}$ & DNA binding \\
\hline 572313862 & $\begin{array}{l}\text { PDZ and LIM domain protein } \\
\text { Zasp-like isoform X1 [Apis dorsata] }\end{array}$ & $\begin{array}{l}\text { Regulator of cell matrix } \\
\text { adhesion; act as an adapter } \\
\text { that brings other proteins } \\
\text { (like kinases) to the } \\
\text { cytoskeleton }\end{array}$ \\
\hline 571525756 & $\begin{array}{l}\text { Uncharacterized protein LOC } 408779 \\
\text { [Apis mellifera] }\end{array}$ & Unknown \\
\hline 66532125 & $\begin{array}{l}\text { Eukaryotic translation initiation } \\
\text { factor } 3 \text { subunit J isoform } 1 \text { [Apis } \\
\text { mellifera] }\end{array}$ & $\begin{array}{l}\text { Required for several steps in } \\
\text { the initiation of protein } \\
\text { synthesis; neurogenesis }\end{array}$ \\
\hline 66511652 & $\begin{array}{l}\text { Asparagine-tRNA ligase, } \\
\text { cytoplasmic-like [Apis mellifera] }\end{array}$ & $\begin{array}{l}\text { Translation; tRNA } \\
\text { aminoacylation for protein } \\
\text { translation }\end{array}$ \\
\hline 571505185 & $\begin{array}{l}\text { NADH dehydrogenase [ubiquinone] } \\
1 \text { beta subcomplex subunit } 11 \text {, } \\
\text { mitochondrial-like [Apis mellifera] }\end{array}$ & $\begin{array}{l}\text { Accessory subunit of the } \\
\text { mitochondrial membrane } \\
\text { respiratory chain NADH } \\
\text { dehydrogenase }\end{array}$ \\
\hline $449,310,784$ & $\begin{array}{l}\text { Dehydrogenase/reductase SDR } \\
\text { family member } 4 \text { [Apis mellifera] }\end{array}$ & $\begin{array}{l}\text { Alcohol metabolic process; } \\
\text { protein tetramerization; } \\
\text { receptor binding }\end{array}$ \\
\hline 571546137 & $\begin{array}{l}\text { Pupal cuticle protein-like [Apis } \\
\text { mellifera] }\end{array}$ & $\begin{array}{l}\text { Chitin-based cuticle } \\
\text { development }\end{array}$ \\
\hline 328783881 & $\begin{array}{l}\text { slit homolog } 2 \text { protein-like isoform } \\
\text { X1 [Apis mellifera] }\end{array}$ & $\begin{array}{l}\text { Nervous system } \\
\text { development; axonogenesis; } \\
\text { axon guidance; olfactory bulb } \\
\text { development }\end{array}$ \\
\hline 571532852 & $\begin{array}{l}\text { UDP-glucuronosyltransferase } \\
\text { 2B13-like [Apis mellifera] }\end{array}$ & $\begin{array}{l}\text { Flavonoid biosynthetic } \\
\text { process; xenobiotic } \\
\text { metabolic process }\end{array}$ \\
\hline
\end{tabular}

\subsection{Functional and Gene Ontology (GO) analysis}

The Blast2GO algorithm (https://www.blast2go.com/) [36] was used to report the biological process categorization of the identified proteins according to Gene Ontology, which contains ontologies and a subset of the terms found in the entire GO (http://www.geneontology.org) [37]. The categories for each classification are nonexclusive (i.e., a number of candidates were found to be localized in more than one cellular compartment). Proteins were classified into functional categories using Blast2GO, and the representation of statistically enriched gene ontology was performed with the algorithm Gene Ontology Enrichment Analysis Software (GOEAST-http://omicslab.genetics.ac.cn/GOEAST/) [38]. The proteins annotated with Blast2GO were submitted as background list to GOEAST, configured to run as a hypergeometric test, adjusted for raw P-values into false discovery rate (FDR) using the Banjamini-Yekutieli method [39].

\subsection{Network analysis}

The list of the identified proteins was subjected to Search Tool for the Retrieval of Interacting Genes/Proteins (STRING V10.0, http://string-db. org) [40] analysis to reveal functional interactions between proteins. Active prediction methods used in our analysis were neighborhood, co-expression, gene fusions, experiments, co-occurrence, databases, and text mining, all with high confidence (0.7). Each node represents a protein, and each edge represents an interaction.

\section{Results}

The experimental approach using a shotgun proteomic analysis of the honeybee brain permitted the reliable identification of 1713 proteins, satisfying a $1 \%$ false discovery rate considering the redundancies in the sequence database (Table $\mathrm{S} 1$ in the online version at http://dx. doi.org/10.1016/j.jprot.2016.05.029.); after applying the maximum parsimony criterion on this list, the number of proteins was reduced to 1353. When the proteomic complements of both groups (control and PER-stimulated) were compared and represented using a Venn diagram (Fig. 1), 1269 proteins were found to be common to both groups, whereas the control group presented 26 unique proteins (Table 1 ) and the PER group presented 58 unique proteins (Table 2). Among the proteins common to both groups, the quantitative analysis revealed 44 differentially abundant proteins, 18 of which were up-regulated (Table 3) and 26 of which were down-regulated (Table 4) in the PER group.

All the identified proteins were then analyzed using the Blast2GO algorithm for categorizing the proteins according to biological process at the fourth level (Table S2 in the online version at http://dx.doi.org/10. 1016/j.jprot.2016.05.029.), and a summary of this analysis is presented in Fig. 2. This result shows that the major biological processes in the honeybee brain are related to transport, the processing of small

Table 3

Proteins that presented up-regulation in PER group, when compared to the control group. Results below listed only proteins obtained for $p$-values $<0.01$.

\begin{tabular}{|c|c|c|c|}
\hline $\begin{array}{l}\text { Accession } \\
\text { code }\end{array}$ & $\begin{array}{l}\text { Fold } \\
\text { Change }\end{array}$ & Protein & Function \\
\hline 20138892 & -5.202536 & Major royal jelly protein 2; Short $=$ MRJP-2 & Plays an important role in honeybee nutrition \\
\hline 572264329 & -3.732665 & Muscle-specific protein 20 -like [Apis dorsata] & Maintenance of the neuromuscular junction; synapse; phosphorylation \\
\hline 380017591 & -2.683406 & $60 \mathrm{~S}$ ribosomal protein L8 [Apis florea] & Translation; centrosome duplication \\
\hline 20138866 & -2.206654 & Major royal jelly protein 1 ; short = MRJP-1 & Caste determination, defense against microorganism infection \\
\hline 572315191 & -1.981185 & $60 S$ ribosomal protein L30-like [Apis dorsata] & Translation; focal adhesion \\
\hline 571544763 & -1.953545 & Putative acyl-CoA-binding protein-like [Apis mellifera] & $\begin{array}{l}\text { Energy metabolism; transport; learning and memory; long-term synaptic } \\
\text { potentiation }\end{array}$ \\
\hline 66552169 & -1.949275 & 60S ribosomal protein L28 [Apis mellifera] & Translation; gene expression; neurogenesis \\
\hline 571500813 & -1.863367 & 40S ribosomal protein S17 [Apis mellifera] & Translation; gene expression; focal adhesion \\
\hline 572302099 & -1.773173 & $60 S$ ribosomal protein L4-like [Apis dorsata]; & Translation; centrosome duplication; gene expression; focal adhesion \\
\hline 571500154 & -1.740841 & Alkyldihydroxyacetonephosphate synthase-like [Apis mellifera] & Ether lipid biosynthesis; oxidation-reduction process \\
\hline 380027232 & -1.643647 & $40 \mathrm{~S}$ ribosomal protein S4 [Apis florea] & Translation; focal adhesion \\
\hline 571550343 & -1.579705 & Fatty acid synthase-like [Apis mellifera] & Regulation of muscle contraction; troponin complex \\
\hline 572299096 & -1.506677 & $\begin{array}{l}\text { Calcium-transporting ATPase sarcoplasmic/endoplasmic reticulum } \\
\text { type-like isoform X4 [Apis dorsata] }\end{array}$ & Glutamine metabolic process \\
\hline 284812514 & -1.480842 & MRJP5 [Apis mellifera] & Caste determination, influence by environmental factors \\
\hline 78101800 & -1.471263 & TPA_exp: troponin T isoform 4 [Apis mellifera] & $\begin{array}{l}\text { Signal peptide; peripheral nervous system axon regeneration; calcium ion } \\
\text { binding }\end{array}$ \\
\hline 380029418 & -1.461579 & Uncharacterized protein LOC100871673 [Apis florea] & Structural constituent of ribosome; translation \\
\hline 94400893 & -1.43053 & Troponin T, skeletal muscle [Apis mellifera] & Structural constituent of ribosome; translation; RNA binding \\
\hline 820837885 & -1.355229 & 40 S ribosomal protein S6 [Apis florea] & $\begin{array}{l}\text { Mitochondrion degradation; regulation of autophagy; multicellular organismal } \\
\text { aging; protein homodimerization activity }\end{array}$ \\
\hline
\end{tabular}


Table 4

Proteins that presented down-regulations in PER group, when compared to the control group. Results below listed only proteins obtained for $p$-values $<0.01$.

\begin{tabular}{|c|c|c|c|}
\hline $\begin{array}{l}\text { Accession } \\
\text { code }\end{array}$ & $\begin{array}{l}\text { Fold } \\
\text { change }\end{array}$ & Protein & Function \\
\hline 66514595 & 1.25493 & Ras-related protein Rab-3 isoformX2 [Apis mellifera] & Multicellular organismal development; \\
\hline 571554588 & 1.259689 & $\begin{array}{l}\text { 2-oxoglutarate dehydrogenase, mitochondrial-like isoform X5 [Apis } \\
\text { mellifera] }\end{array}$ & Tricarboxylic acid cycle; oxidation-reduction process \\
\hline 335892820 & 1.383799 & Pyruvate dehydrogenase E1 component, mitochondrial [Apis mellifera] & Protein transport; signal transduction; GTP binding \\
\hline 571575167 & 1.431369 & NADP-dependent malic enzyme isoform X1 [Apis mellifera] & Proteasome-mediated ubiquitin-dependent protein catabolic process \\
\hline 507418852 & 1.439915 & Rab escort protein [Apis mellifera] & Transferase activity; cell cycle \\
\hline 380028013 & 1.466512 & ATP-dependent RNA helicase WM6 [Apis florea] & mRNA export \\
\hline 380026816 & 1.496064 & Mitochondrial fission 1 protein [Apis florea] & Apoptotic process; peroxisome fission \\
\hline 571537241 & 1.517303 & $\begin{array}{l}\text { Transcriptional activator protein Pur-beta-B-like isoform X2 [Apis } \\
\text { mellifera] }\end{array}$ & Cell differentiation; cell proliferation \\
\hline 295422209 & 1.532515 & Unnamed protein product [Apis mellifera] & Intracellular signal transduction; protein ubiquination \\
\hline 66561330 & 1.539567 & Phosphoglucomutase isoform X3 [Apis mellifera] & Breakdown and synthesis of glucose; cell adhesion \\
\hline 820856961 & 1.552771 & EH domain-containing protein 3 [Apis florea] & Endocytic transport \\
\hline 572263147 & 1.565997 & Proton-coupled amino acid transporter 1-like isoform X1 [Apis dorsata] & Neutral amino acid/proton symporter; transport \\
\hline 328779221 & 1.571725 & UDP-glucuronosyltransferase 1 -3-like [Apis mellifera] & Elimination of potentially toxic xenobiotics and endogenous compounds \\
\hline 380030413 & 1.575212 & Failed axon connections [Apis florea] & Neurogenesis \\
\hline 380016147 & 1.614437 & Uncharacterized protein LOC100867355 [Apis florea] & Unknown \\
\hline 571514456 & 1.724201 & RNA-binding protein squid-like [Apis mellifera] & mRNA splicing, via spliceosome \\
\hline 66546988 & 1.744358 & $D$-arabinitol dehydrogenase 1 -like [Apis mellifera] & Unknown \\
\hline 571573277 & 1.836049 & $\begin{array}{l}\text { CDGSH iron-sulfur domain-containing protein } 2 \text { homolog isoform X1 } \\
\text { [Apis mellifera] }\end{array}$ & Depression of endoplasmic reticulum $\mathrm{Ca}^{2+}$ stores during autophagy \\
\hline 373205486 & 1.84741 & Ras-related protein Rab-8 A [Apis cerana] & Regulators of intracellular membrane trafficking; transport \\
\hline 572316658 & 1.915055 & Proteasome subunit alpha type-5-like [Apis dorsata] & $\begin{array}{l}\text { Proteasome-mediated ubiquitin-dependent protein catabolic process; } \\
\text { apoptotic process. }\end{array}$ \\
\hline 66547760 & 1.971948 & Dihydropteridine reductase isoform X2 [Apis mellifera] & Cofactor for phenylalanine, tyrosine, and tryptophan hydroxylases \\
\hline 571550590 & 1.982327 & Glutaminase; mitochondrial isoformX1 [Apis mellifera] & Regulates the levels of the neurotransmitter glutamate in the brain \\
\hline 571518500 & 2.022802 & 40S ribosomal protein S21-like isoform X1 [Apis mellifera] & Translation initiation factor; gene expression \\
\hline 380024395 & 2.219811 & Glutaredoxin 3 [Apis florea] & Cell redox homeostasis \\
\hline 66506276 & 2.350153 & Uncharacterized protein LOC551541 [Apis mellifera] & Unknown \\
\hline 380025630 & 2.702238 & Calumenin [Apis florea] & Peripheral nervous system axon regeneration \\
\hline
\end{tabular}

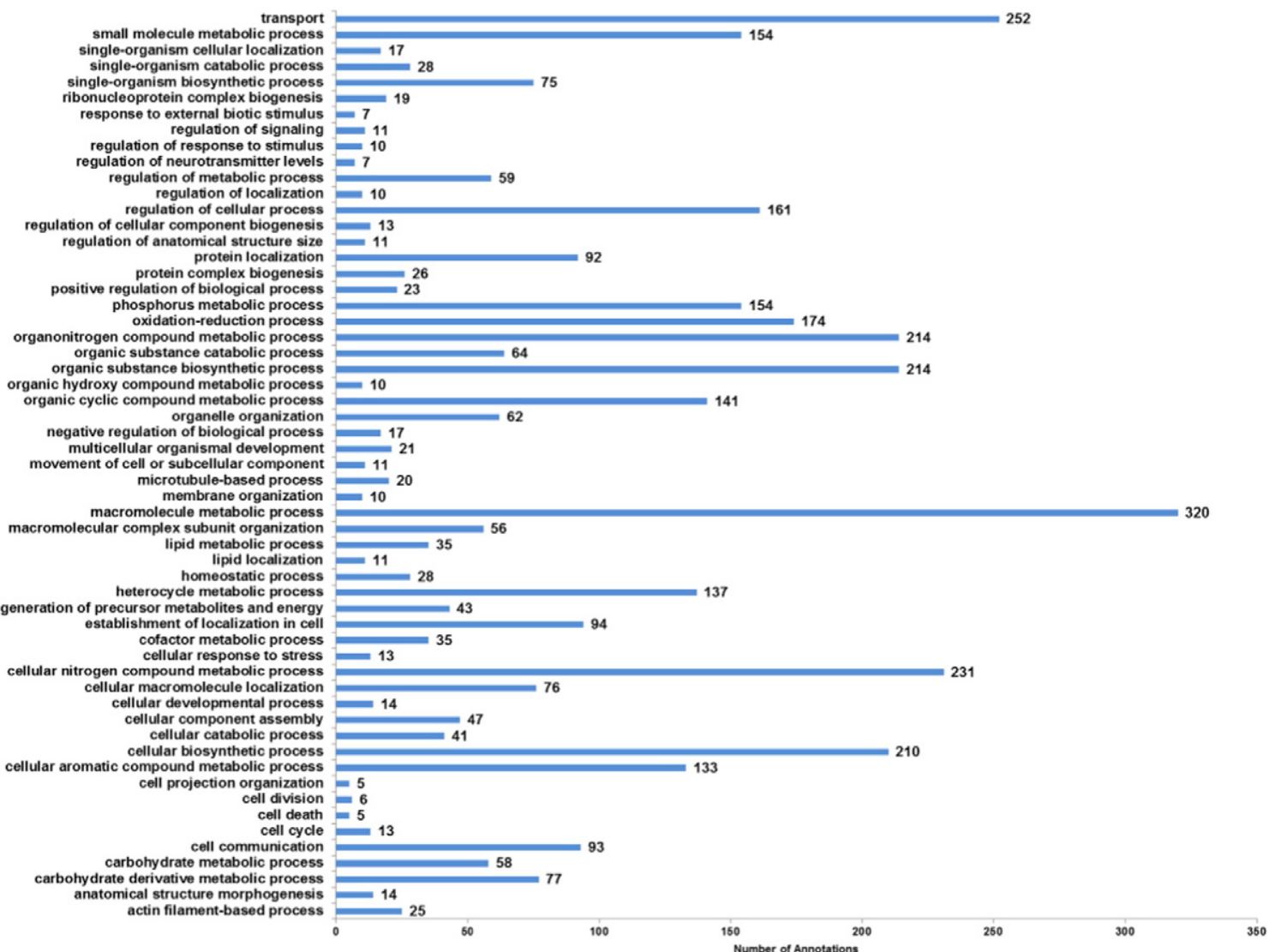

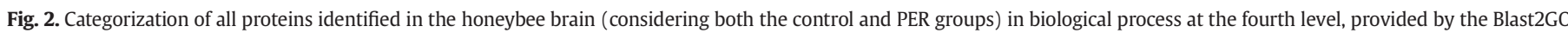
algorithm. 


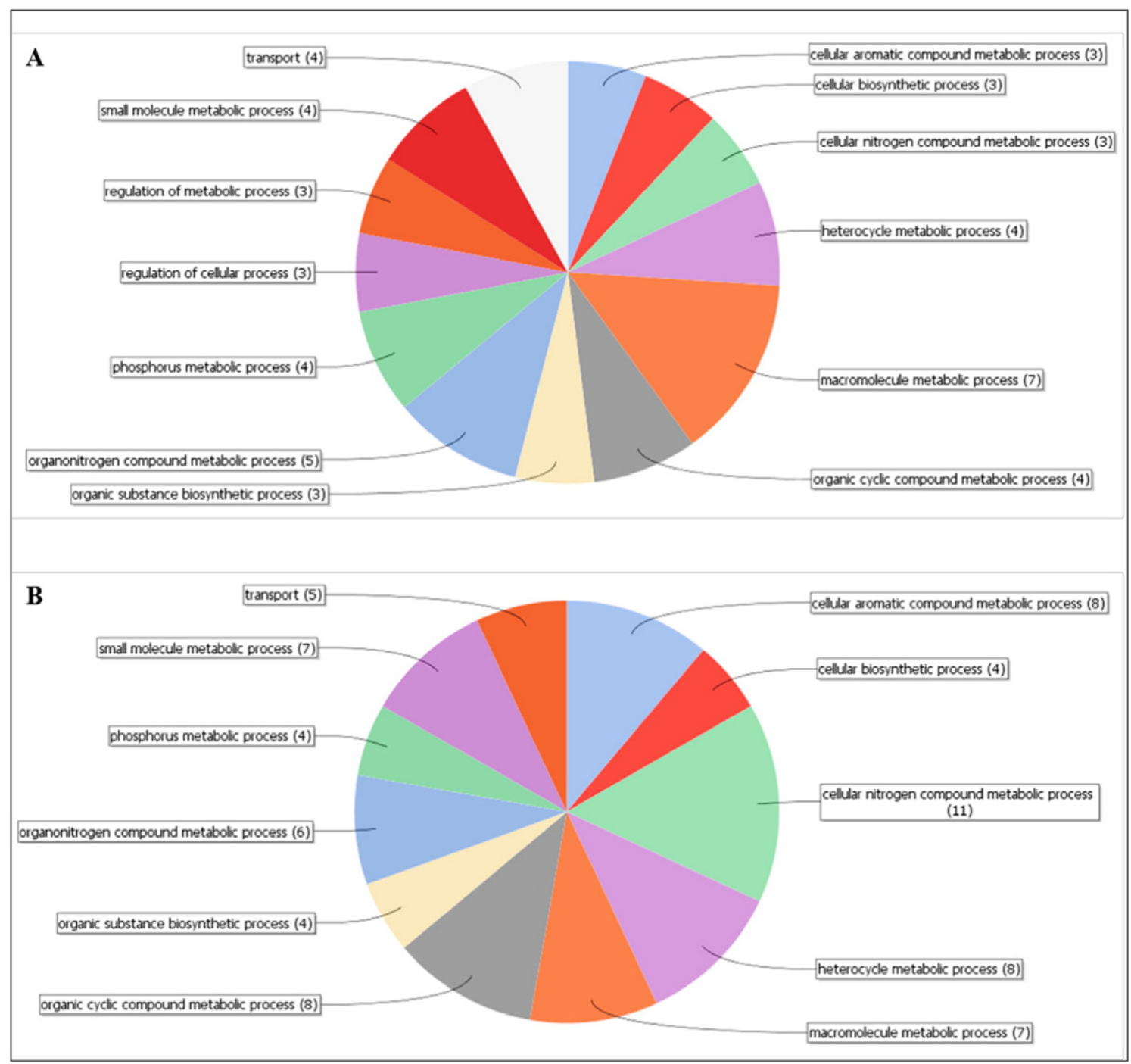

Fig. 3. Categorization according to biological process at the fourth level using the Blast2GO algorithm for the proteins unique to each group: $(A)$ proteins identified only in the control group; (B) proteins identified only in the PER group.

molecules, the regulation of cellular processes, phosphorus metabolism, ox-redox processes, the biosynthesis/catabolism of organic substances, the biosynthesis of proteins, and the metabolism of nitrogenated compounds. The Blast2GO analysis for the unique proteins is shown in Fig. $3 \mathrm{~A}$ (for the control group) and 3B (for the PER group). This analysis revealed that the 26 unique proteins in the control group belong to 13 categories of biological processes, whereas the 58 unique proteins from the PER group belong to 11 different biological processes. The Blast2Go analysis for the differentially expressed proteins is shown in Fig. 4A (for the proteins down-regulated in the PER group) and 4B (for the proteins up-regulated in the PER group); this analysis revealed that the 26 down-regulated proteins belong to 11 categories of biological processes, whereas the 18 up-regulated proteins belong to six categories of processes.

The analysis of enriched GO terms for the unique proteins revealed 5 and 4 different biological and/or molecular processes in the brains of the individuals both of the control group (naive) and in the PER group, respectively. The enriched GO terms of the control group were protein import into nucleus (GO:0006606), ATP metabolic process (GO:0046034), methionine metabolic process (GO:0006555), protein ubiquination (GO:0016567), and protein deubiquitination (GO:0016579) (Fig. S1 in supplementary information). Meanwhile, among the unique proteins from the brains of individuals of PER group, the enriched GO terms were RNA processing (GO:0006396), translation (GO:0006412), nucleotides metabolic process (GO:0009117), and protein macromolecular assembly (GO:0034622) (Fig. S2 in supplementary information).

The analysis enriched of GO terms detected 5 and 4 biological and molecular processes among the down-regulated and up-regulated proteins of PER group, respectively. The enriched GO terms of the downregulated proteins were intracellular transport (GO:0046907), signal transduction (GO:0007165), tricarboxylic acid catabolic process (GO:0072352), regulation of purine nucleobase metabolic process (GO:0006141), and modification-dependent catabolic process (GO:0019941) (Fig. S3 in supplementary information). Meanwhile, among the up-regulated proteins the enriched GO terms were intracellular transmembrane proteins transport (GO: 0006725), regulation of mRNA metabolic process (GO:1903311), and innate immune response (GO: 0045087) (Fig. S4 in Supplementary information).

The proteins establish regulatory networks by interacting with each other [36]; thus, the proteomic complement of the honeybee brain was analyzed using the String V10.0 algorithm and searching for proteinprotein interactions, specifically for A. mellifera; the results are shown in Figs. 5-8. Thus, when the 26 proteins unique to the control group were submitted to the analysis with the String algorithm, 9 were identified to participate with protein networks, as shown in Fig. 5A; the networks identified are related to the regulation of cell death (Fig. 5B), differentiation of nervous system (Fig. 5C), and protein catabolism (Fig. $5 \mathrm{D}$ ). When the 58 proteins unique to the PER group were analyzed with 


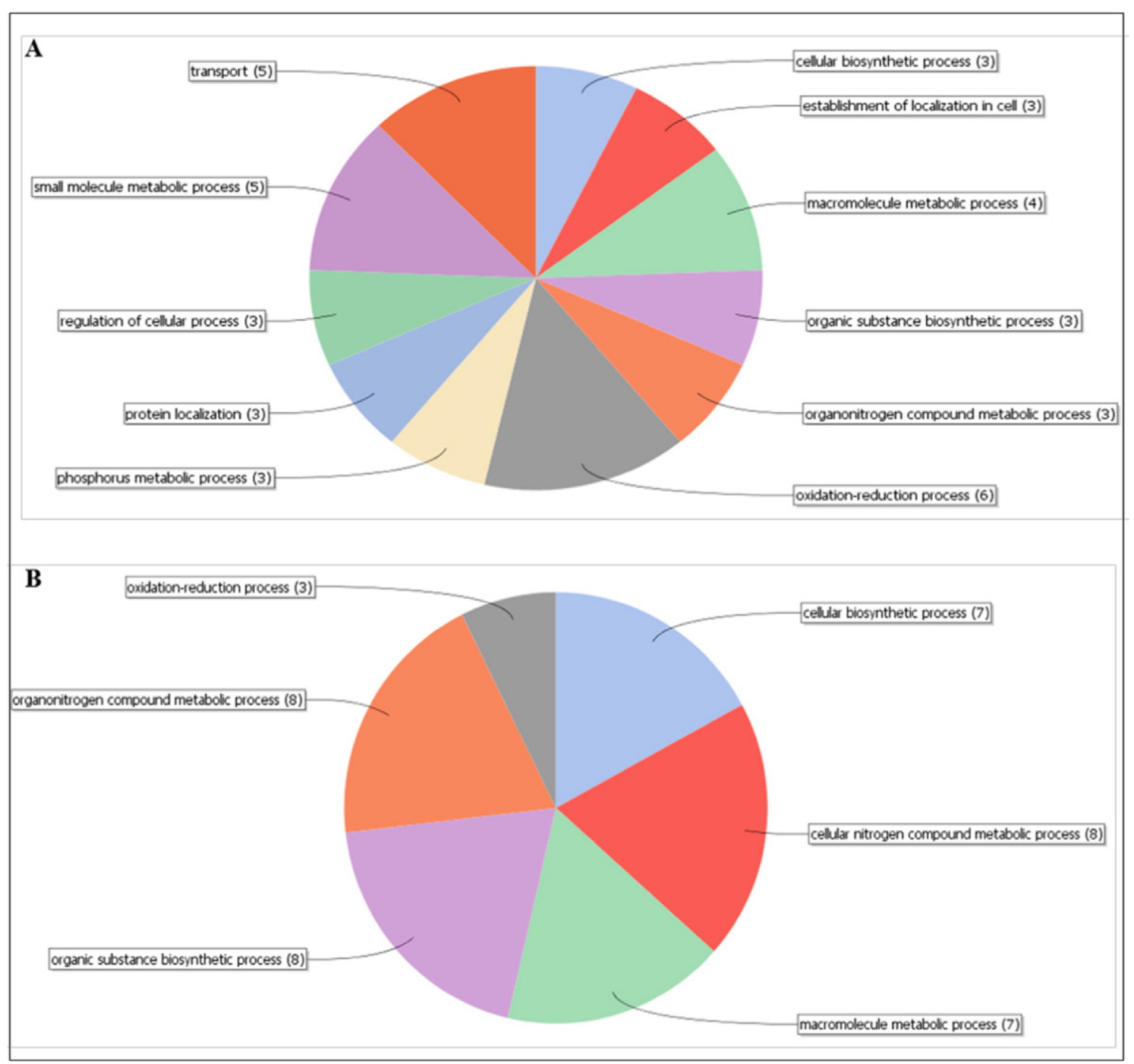

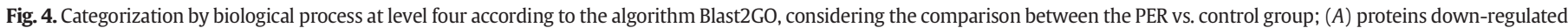
in PER group and $(B)$ proteins up-regulated in the PER group.

String, 19 were identified to participate in protein networks (Fig. 6A); these networks were related to the regulatory circuits of biosynthetic processes (Fig. 6B), carbohydrate metabolism (Fig. 6C), and nervous system differentiation (Fig. 6D), general metabolism (Fig. 6E), and a response specific to the stimulus (perception of the odor of sucrose) (Fig. 6F).

Proteins down-regulated in the brains of bees in the PER group were submitted to a search in String DB, and 12 of these proteins were identified to participate in protein networks (Fig. 7A); the networks identified were related to the regulation of anatomical development and cell differentiation (Fig. 7B), general biosynthetic processes (Fig. 7C), and general biological regulation (Fig. 7D). The 18 proteins up-regulated in the PER group were also analyzed with String, and 10 participated in protein networks (Fig. 8A); the networks identified were related to the regulation of anatomical structure development (Fig. 8B), cytoskeleton organization (Fig. 8C), and general biosynthetic processes (Fig. 8D).

\section{Discussion}

The PER is considered a US in honeybees and is frequently used in behavioral experiments to evaluate the ability of these insects to establish associations between the US and CS; bees are generally rewarded with a carbohydrate solution $[14,15,16,17]$. These experiments usually evaluate biochemical and/or genic changes at the final of two types of insect manipulations, i.e., the individuals are trained for the PER in association with a second behavior (such as recognizing the size/color of an object or even an odor); if an association between the processes is established by the bees, the individuals extend their proboscis to be rewarded with a carbohydrate solution. Thus, the biochemical and/or genetic variables observed reflect the overall changes induced by both insect manipulations. PER alone is an important reflex in part of the experimental strategy to access honeybees' ability to learn and acquire memory; thus, it is necessary to identify the biochemical changes induced in honeybee brains by this reflex.

When investigating this process, it is important to consider that the olfactory memory of worker honeybees was initially acquired during visits to the flowers for collecting nectar; this memory is then transferred to the paradigm in the laboratory during the experiments [17]. Therefore, a component of the olfactory memory in the brain of worker bees is present at the application of the paradigm in the laboratory. To access the major biochemical processes occurring during the execution of PER in the brains of honeybee workers, the present investigation profiled the proteomic complement of 20-day-old bees, trained for the execution of PER and compared it with untrained bees.

A total of 1353 proteins (maximum parsimony) were reliably identified in the brains of both groups (1295 proteins were identified in the control group; 1327 proteins were identified in the PER group). Among these proteins, 26 were unique to the control group (Table 1), whereas 58 were unique to the PER group (Table 2). The interrogation 
A
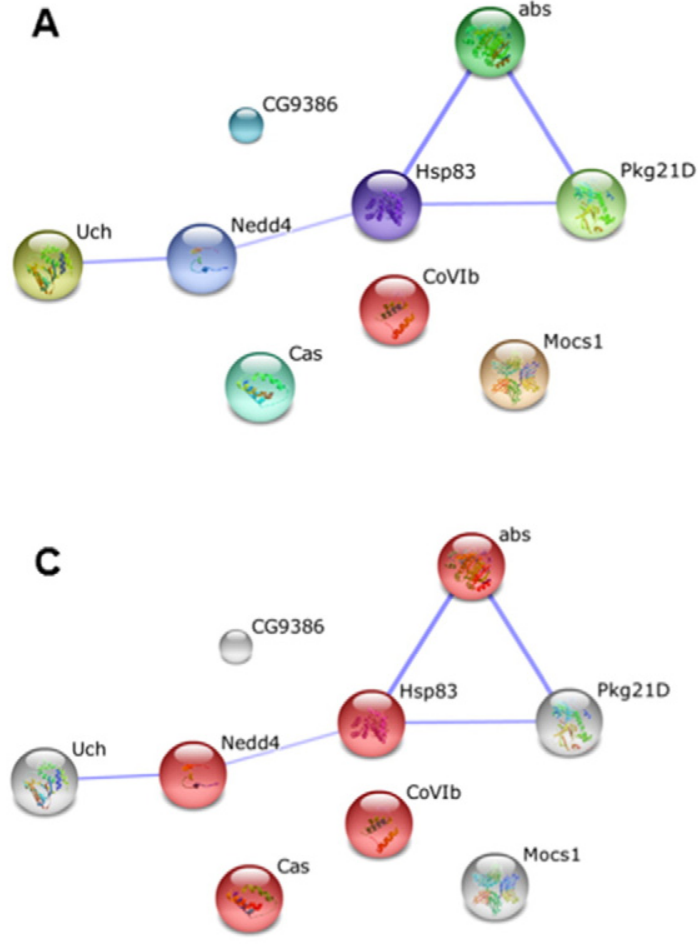

- CoVlb Cytochromecoxidase

Q Mocs1 Is oform Mocs $1 \mathrm{a}$ and is oform Mocs $1 \mathrm{~b}$ probably forma complex that catalyzes the conversion of 5'-GTP to cyclic pyranopterin monophosphate

$\theta$ Uch Ubiquitin-protein hydrolase is involved both in the processing of ubiquitin precursors and of ubiqutinatedproteins.

(9 Pk21D cGMP-dependent protein kinase

$\theta$ cas Transcription factor that specifies expression of key genes in developing central nervous system (CNS).

(9) abs Is essential for the directed andfasciculated early outgrowth of the bolwig nerves Plays a role during morphogenetic process, apoptosis and the establishment of cell polarity.
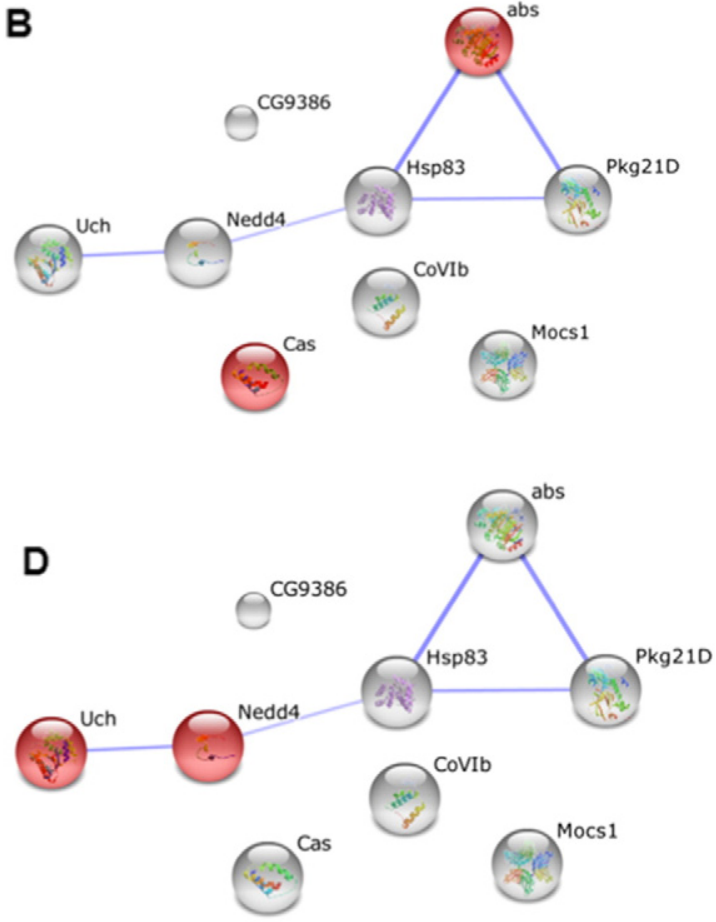

O CG9386 Probable adenosyl-L-methionine (AdoMet)-dependenttRNA (uracil-O(2)-) methyltransferase

- Nedd4 Essential E3 ubiquatin-protein ligase which accepts ubiquitin from an E2 ubiquitinconjugating enzyme in the form of a thioester and then directly transfers the ubiquitin to targeted substrates.

Hsp83 Molecular chaperone that promotes the maturation, structural maintenance and proper regulation of specifictarget proteins involvedfor instance in cell cycle control and signal transdudion.

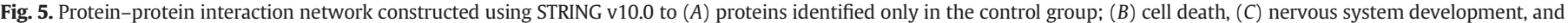
neuron differentiation and $(D)$ proteolysis involved in the cellular protein catabolic process. Proteins with stronger associations are linked with thicker lines.

of Blast2GO DB for these unique proteins revealed interesting metabolic features, as shown in Fig. 3:

i) 11 proteins were related to the metabolism of nitrogenated compounds in the PER group (versus only 3 proteins in the control group).

ii) 8 proteins were related to the metabolism of heterocyclic compounds in the PER group, whereas only 4 proteins were related to this metabolism in the control group.

iii) 8 proteins were related to the metabolism of aromatic compounds in the PER group, whereas only 3 proteins were related to this metabolism in the control group.

iv) 8 proteins were related to the metabolism of cyclic compounds in the PER group, whereas only 4 proteins were related to this metabolism in the control group.

Therefore, 35 of the 58 proteins unique to the brains of the individuals of PER group are related to the metabolism of cyclic/heterocyclic/ aromatic compounds; however, 14 of the 26 proteins unique to the control group are related to these transformations, suggesting that the metabolic transformations of compounds containing ringed structures are particularly important during for the PER. These observations include the metabolism of some neurophysiologically important classes of compounds such as pyridines (niacin), pyrroles (pyrrole-2-carboxylate), purines (adenosine), pyrimidines (uridine-5'-monphosphate), indoles (serotonin, tryptamine), imidazoles (biotin), and phenylated compounds (dopa and dopamine).

Among the 1269 proteins common to both groups, 18 were up-regulated in the brains of individuals in the PER group (Table 3), 26 were down-regulated in the individuals of the PER group (Table 4). When the Blast2GO DB was prompted with these proteins, some interesting metabolic features were observed (as shown in Fig. 4):

i) A total of 16 of the up-regulated proteins were related to metabolic processes of nitrogenated compounds, whereas only 3 down-regulated proteins belonged to this process.

ii) 3 down-regulated proteins were related to the metabolism of phosphorylated metabolites.

Apparently, the observation that there are more down-regulated proteins than up-regulated ones in the PER assay appears to be consistent with previous reports in which the use of the PER was associated with different CS resulted in more down-regulated than up-regulated genes $[25,26,27]$. We highlight that among the major up-regulated brain PER group, the royal jelly proteins (Table 3 ), the proteins MRJP1 and -2 , were more abundant in the brain of nurse bees when compared to the foragers ones [41].

The complex phenotypic traits in honeybees appear to result from an organized clusterization of proteins to form interactive networks that activate and regulate a series of functional circuits [42]; the 

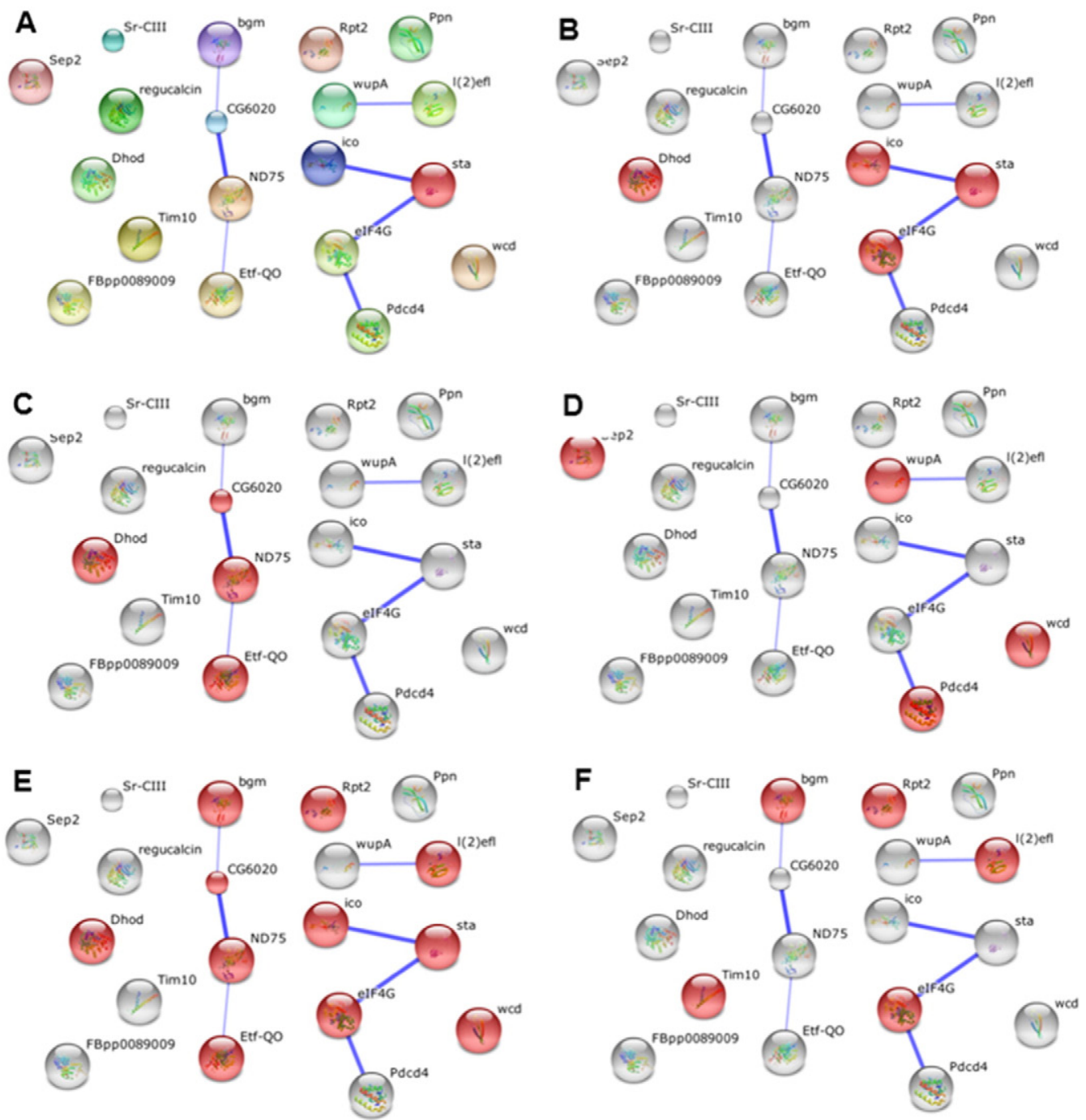

\begin{tabular}{|c|c|}
\hline$\Theta$ sta & $\begin{array}{l}\text { Required for the assembly and/or stability of the } 40 \mathrm{~S} \\
\text { ribosomal subunit. }\end{array}$ \\
\hline ND75 & $\begin{array}{l}\text { Core subunit of the mitochondrialmembrane } \\
\text { respiratory chain } \mathrm{NADH} \text { dehydrogenase (ComplexI) } \\
\text { that is believed to belongto the minimal assembly } \\
\text { required for catalysis. }\end{array}$ \\
\hline$\ominus \operatorname{Tim} 10$ & $\begin{array}{l}\text { Mitochondrial intermembrane chaperone that } \\
\text { participates in the import and insertion of multi-pass } \\
\text { transmembrane proteins into the mitochondrial inner } \\
\text { membrane. }\end{array}$ \\
\hline I(2)efl & Vital role in embryonic development \\
\hline regucalcin & regucalcin \\
\hline wupA & $\begin{array}{l}\text { Involved in the development and maintenance of } \\
\text { muscle and nervous system. }\end{array}$ \\
\hline$\Theta \mathrm{Sr}-\mathrm{CIII}$ & Scavenger receptor \\
\hline$\ominus$ CG6020 & CG6020 gene product from transcript CG6020-RA \\
\hline$\theta$ ico & $\begin{array}{l}\text { Catalyzes the coordinated movement of the two tRNA } \\
\text { molecules, the mRNA and conformational changes in } \\
\text { the ribosome. } \\
\text { complex which is involved in protein synthesis. }\end{array}$ \\
\hline
\end{tabular}

\begin{tabular}{|c|c|}
\hline$\ominus$ bgm & Mediates activation of very-long-chain fatty acids. \\
\hline Sep2 & Involved in cytokinesis. \\
\hline Rpt2 & $\begin{array}{l}\text { The } 26 \mathrm{~S} \text { protease is involved in the ATP-dependent } \\
\text { degradation of ubiquitinated proteins. }\end{array}$ \\
\hline wed & $\begin{array}{l}\text { Regulation of cell size by ribosome synthesis is an } \\
\text { important parameter for stem cellmaintenance and } \\
\text { function. }\end{array}$ \\
\hline Etf-QO & $\begin{array}{l}\text { Electron transfer flayoprotein-ubiquinone } \\
\text { oxidoreductase }\end{array}$ \\
\hline FBpp0089009 & asparagine synthetase \\
\hline elF $4 \mathrm{G}$ & eukaryotictranslation initiationfactor $4 \mathrm{G}$ \\
\hline Pdcd 4 & Programmed cell death 4 ortholog \\
\hline Dhod & $\begin{array}{l}\text { Catalyzes the conversion of dihydroorotate to orotate } \\
\text { with quinone as electron acceptor }\end{array}$ \\
\hline Ppn & Papilin \\
\hline
\end{tabular}

Fig. 6. Protein-protein interaction network constructed using STRING v10.0 to $(A)$ proteins identified only in the PER group; $(B)$ biosynthetic process, $(C)$ carbohydrate derivative metabolic process, $(D)$ nervous system development, and neuron differentiation, $(E)$ primary metabolic process, and $(F)$ response to stimulus. Proteins with stronger associations are linked with thicker lines. 
A

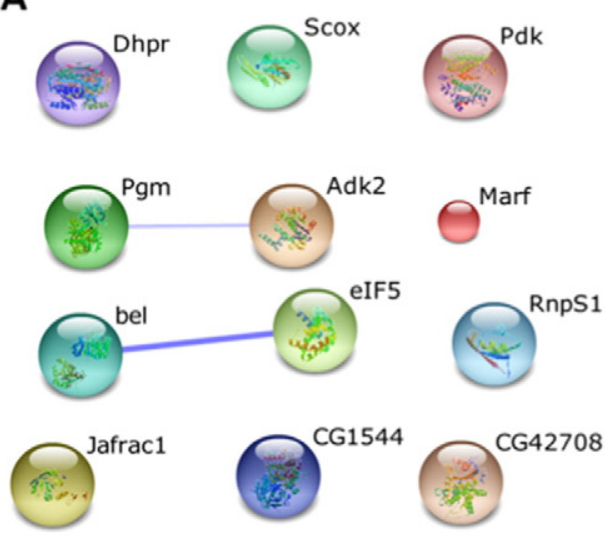

C

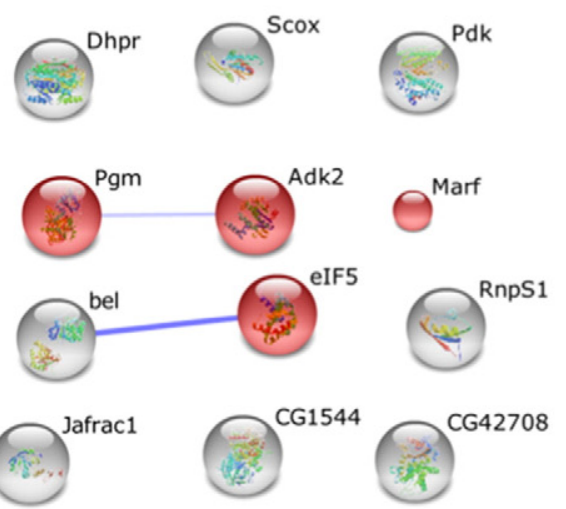

Marf $\begin{aligned} & \text { Essential transmembrane GTPase, which mediates } \\ & \text { mitochondrial fusion. }\end{aligned}$
Adk2 $\begin{aligned} & \text { Plays an important role in cellular energy homeostasis and in } \\ & \text { adenine nucleotide metabolism. }\end{aligned}$
Jafrac1 Involved in redox regulation of the cell. May play an importan
role in eliminating peroxides generated during metabolism.
B
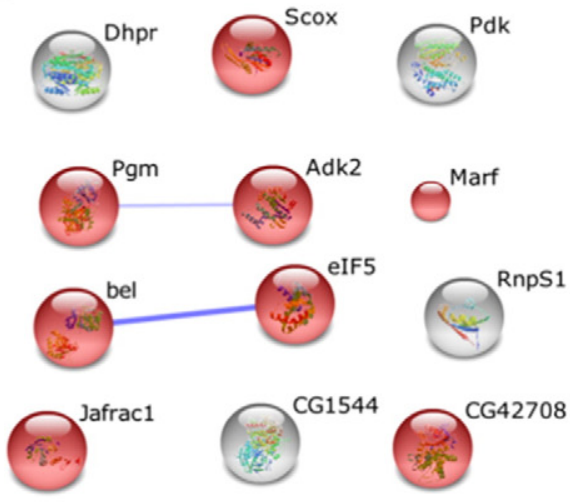

D
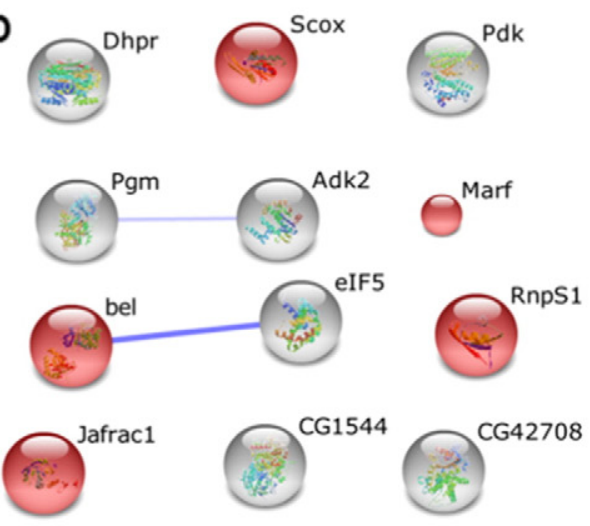

bel Also required for RNA interference (RNAi), double-stranded RNA induces potent and specific gene silencing, by acting downstreamof dsRNA internalization.

\begin{tabular}{|c|c|}
\hline RnpS1 & RNA-binding protein S1 \\
\hline CG1544 & $\begin{array}{l}\text { The 2-oxoglutarate dehydrogenase complex catalyzes the } \\
\text { overall conversion of 2-oxoglutarate to succinyl-C } \alpha A \text { and } \\
C O(2) \text {. }\end{array}$ \\
\hline Dhpr & Dihydropteridine redudase \\
\hline Pdk & $\begin{array}{l}\text { Inhibits the mitochondrial pyruvate dehydrogenase complex by } \\
\text { phosphorylation of the E1 alpha subunit, thus contributing to } \\
\text { the regulation of glucosemetabolism. }\end{array}$ \\
\hline
\end{tabular}

CG42708 CG42708 geneproduct fromtranscript CG42708-RA.

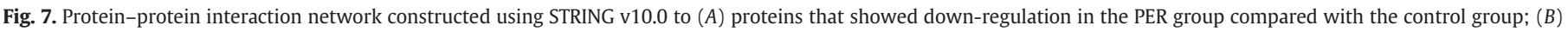

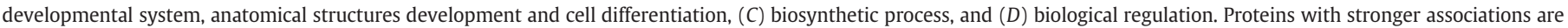
linked with thicker lines.

complexity of these networks may increase due to the multiple functions presented by the most proteins. To investigate the potential formation of proteomic networks, the unique proteins in addition to those differentially expressed were analyzed with the algorithm String v10.0; the results are summarized in Figs. 5-8. Notably, there is no specific databank of protein-protein interactions for honeybees in other algorithms used for simulating these interactions. The data available in String DB for the A. mellifera taxa are reduced and the number of specific networks formed was also relatively reduced, but these networks simulations are consistent. We did not simulate any interaction using data from taxa other than A. mellifera. An interpretation of the results shown in Fig. 5 reveals that nine of the unique proteins of the control group formed a small network related to the control of cell death (Fig. 5B), and nervous system differentiation (Fig. 5C), and proteolysis associated with protein catabolism (Fig. 5D). These processes constitute normal regulatory circuits necessary to the brain plasticity of the worker bees, which are primarily related to the temporal polyethism characteristics of these insects. When the proteins unique to the brain of the individuals of the PER group were analyzed with String, they formed a network involved in the regulation of five different regulatory circuits (Fig. 6B-F): general biosynthetic processes (6B), the metabolism of carbohydrates (Fig. 6C), nervous 

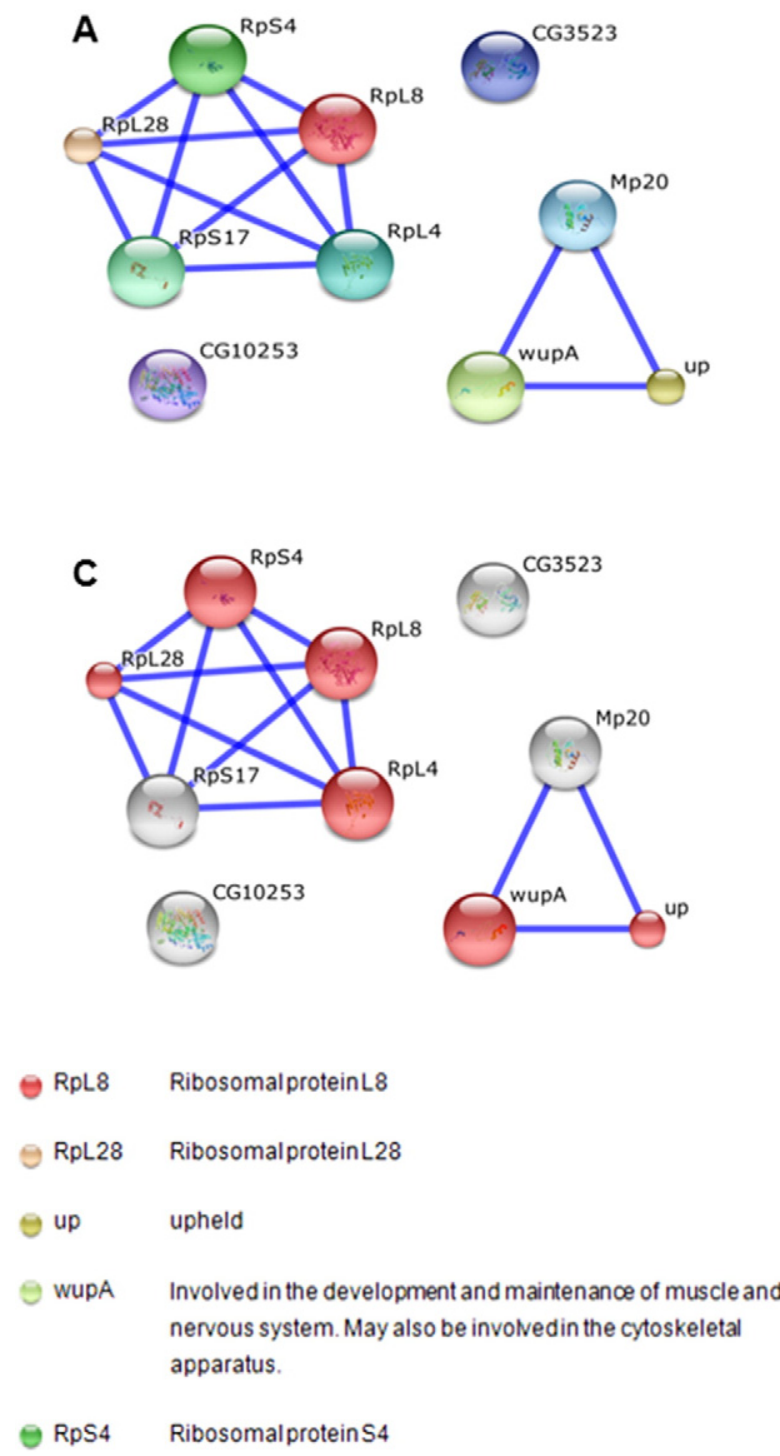
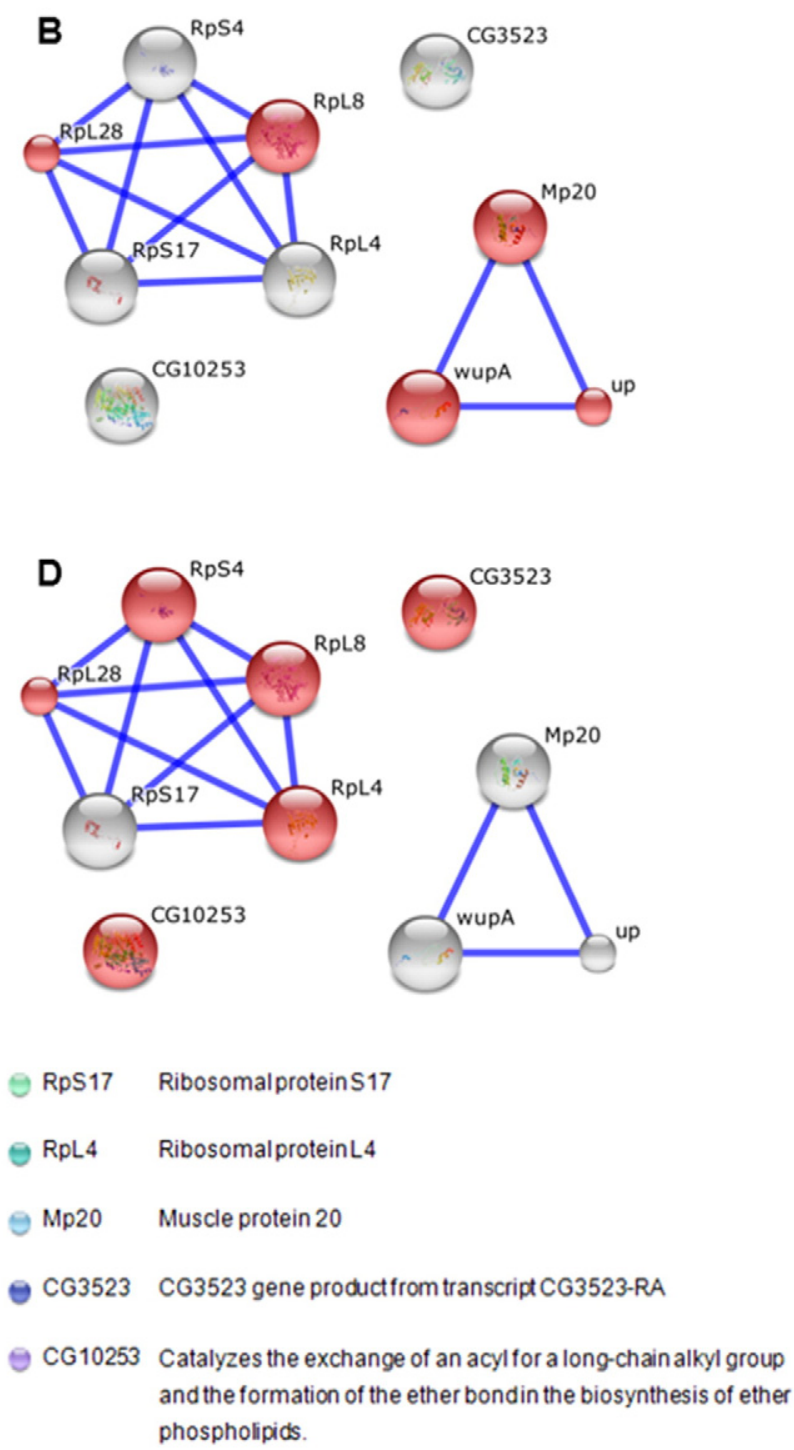

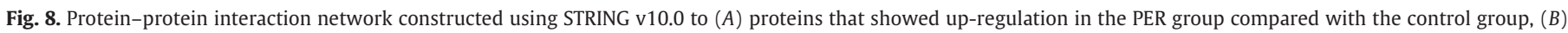

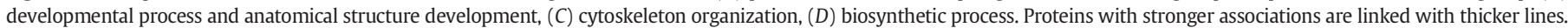

system development (Fig. 6D), primary metabolism (Fig. 6E), and a specific response to the stimulus (Fig. 6F). Among these regulatory circuits, i) the metabolism of carbohydrates, ii) the development of nervous system, and iii) specific response to the stimulus warrant emphasis. The honeybee brain appears to adapt to the PER, requiring energy via carbohydrate metabolism. Regarding the specific response to the stimulus (recognizing the odor of sucrose and extending the proboscis), the proteins involved in this response (mitochondrial chaperone, protein vital embryonic development, proteins responsible for the activation of fatty acids, and translation factors) appear to be related to the synthesis of growth factors. These processes are apparently related to the brain adaption to a specific US.

The results of the analysis of enriched GO terms are indicating that the training of honeybee workers for PER reflex behavior seems to trigger different responses in honeybee brain, with different types of regulation of protein expression.

The networking analysis performed for the down-regulated proteins in the brains of the individuals of the PER group (Fig. 7B-D) revealed three regulatory circuits: i) anatomic development and cell differentiation (Fig. 7B), ii) a general biosynthetic process (Fig. 7C), and iii) general biological process regulation (Fig. 7D). The analysis with the String algorithm of the up-regulated proteins in the brains of individuals in the PER group revealed the formation of a small network related to the regulation of three processes (Fig. 8B-D): i) anatomic development (Fig. 8B), ii) cytoskeleton development (Fig. 8C), and iii) general biosynthetic processes (Fig. 8D). The up-regulation of anatomic and cytoskeleton development is of notable importance.

The results may indicate some degree of cell differentiation. Some regions of the honeybee brain are known to have special importance in terms of odorant memory, especially the mushroom bodies, which have a remarkable structural plasticity according to the age and/or specific environment of the honeybees [43].

In the present investigation were observed different protein networks related to the differentiation of nervous system, but no process of neurogenesis was reported. It was reported in the literature that the neurogenesis is uncommon in the brain of adult honeybees and that the behavioral development must depend of a series of other developmental processes [44], such as those reported above in the present study. The results above demonstrate that brain proteomics is linked to PER behavior and that some changes in brain proteins expression may mediate changes in the US-related behavior, as similarly proposed for other types of behaviors in honeybees [45]. 


\section{Conclusions}

The brains of honeybee workers submitted to a PER assay underwent a series of specific metabolic transformations and various biological processes at the cellular level to adapt the insects' brains to coordinate odor recognition and to associate this odor with a reflex behavior to perform a US (proboscis extension). Thus, the comparative analysis of the proteomic profiles for the brains of honeybee workers submitted and not submitted to PER assay revealed that the brains of PER-stimulated individuals demonstrated an activation of the metabolism of cyclic/heterocyclic/aromatic compounds in parallel with the metabolism of nitrogenated compounds; this was followed by the downregulation of proteins involved in the metabolism of phosphorylated metabolites and the up-regulation of the proteins related to the metabolism of carbohydrates. This likely occurred to supply metabolic energy for the cellular processes necessary to adapt the brain to the PER. Regarding cellular processes, the proteomic profile was stimulated by the PER, which indicates a series of various stimuli to the differentiation of the nervous system; however, there was a down-regulation in the anatomic development and cell differentiation in other neurons, followed by the up-regulation of proteins involved with anatomic and cytoskeleton development.

\section{List of abbreviations}

$\begin{array}{ll}\text { PER } & \text { Proboscis extension reflex } \\ \text { US } & \text { Unconditioned stimulus } \\ \text { CS } & \text { Conditioned stimulus } \\ \text { ACN } & \text { Ecetonitrile } \\ \text { SPE } & \text { Solid-phase extraction } \\ \text { LC } & \text { Liquid chromatography } \\ \text { MS } & \text { Mass spectrometry } \\ \text { ETD } & \text { Electron-transfer dissociation } \\ \text { DMSO } & \text { Dimethyl sulfoxide }\end{array}$

Supplementary data to this article can be found online at http://dx. doi.org/10.1016/j.jprot.2016.05.029.

\section{Conflicts of interest}

The authors declare no conflicts of interest.

\section{Transparency document}

The Transparency document associated with this article can be found, in online version.

\section{Acknowledgments}

This work was supported by grants from FAPESP (Proc. 2011/516841) and CNPq. The authors thank the Program for Technological Development in Tools for Health, PDTIS-FIOCRUZ, for the use of its facilities (RPT02H PDTIS/Carlos Chagas Institute-Fiocruz, Paraná). The authors thank Dr. Michel Batista for running the samples in the mass spectrometer. M.S.P., O.M., and P.C.C. are researchers from the National Research Council of Brazil-CNPq; A.R.S.M. and M.P. are post-graduation fellows from FAPESP; T.C.R., and J. S. G. F are post-doctorate fellows.

\section{References}

[1] L.Z. Zhang, W.Y. Yan, Z.L. Wang, Y.H. Guo, Y. Yi, S.W. Zhang, Z.J. Zeng, Differential protein expression analysis following olfactory learning in Apis cerana, J. Comp. Physiol. A. 201 (2015) 1053-1061.

[2] R. Menzel, Das Ged"achtnis der Honigbiene f ur Spektralfarben, J. Comp. Physiol. A, Neural. Behav. Physiol. 60 (1968) 82-102.

[3] M.V. Srinivasan, Pattern recognition in the honeybee: recent progress, J. Insect Physiol. 40 (1994) 183-194.
[4] M. Giurfa, S. Zhang, A. Jenett, R. Menzel, M.V. Srinivasan, The concepts of 'sameness' and 'difference' in an insect, Nature 410 (2001) 930-932.

[5] S. Zhang, F. Bock, A. Si, J. Tautz, M.V. Srinivasan, Visual working memory in decision making by honey bees, Proc. Natl. Acad. Sci. U. S. A. 102 (2005) 5250-5255.

[6] H.J. Gross, M. Pahl, A. Si, H. Zhu, J. Tautz, S. Zhang, Number-based visual generalisation in the honeybee, PLoS One 4 (2009), e4263.

[7] A. Avargués-Weber, A.G. Dyer, M. Combe, M. Giurfa, Simultaneous mastering of two abstract concepts by the miniature brain of bees, Proc. Natl. Acad. Sci. U. S. A. 109 (2012) 7481-7486.

[8] S. Zhang, S. Schwarz, M. Pahl, H. Zhu, J. Tautz, Honeybee memory: a honeybee knows what to do and when, J. Exp. Biol. 209 (2006) 4420-4428.

[9] M. Pahl, H. Zhu, W. Pix, J. Tautz, S. Zhang, Circadian timed episodic-like memory-a bee knows what to do when, and also where, J. Exp. Biol. 210 (2007) 3559-3567.

[10] R. Menzel, M. Hammer, U. Müller, H. Rosenboom, Behavioral, neural and cellular components underlying olfactory learning in the honeybee, J. Physiol. Paris 90 (1996) 395-398.

[11] L.Z. Zhang, S.W. Zhang, Z.L. Wang, W.Y. Yan, Z.J. Zeng, Crossmodal interaction between visual and olfactory learning in Apis cerana, J. Comp. Physiol. A. 200 (2014) 899-909.

[12] T.S. Collett, P. Graham, V. Durier, Route learning by insects, Curr. Opin. Neurobiol. 13 (2003) 718-725.

[13] M.V. Srinivasan, S. Zhang, H. Zhu, Honeybees link sights to smells, Nature 96 (1998) 637-638.

[14] M. Giurfa, J.C. Sandoz, Invertebrate learning and memory: fifty years of olfactory conditioning of the proboscis extension response in honeybees, Learn. Mem. 19 (2012) 54-66.

[15] M. Hammer, R. Menzel, Learning and memory in the honeybee, J. Neurosci. 15 (1995) 1617-1630.

[16] G. Braun, G. Bicker, Habituation of an appetitive reflex in the honeybee, J. Neurophysiol. 67 (1992) 588-598.

[17] B. Gerber, N. Geberzhan, F. Hellstern, J. Klein, O. Kowalsky, D. Wurstenberg, R. Menzel, Honey bees transfer olfactory memories established during flower visits to a proboscis extension paradigm in the laboratory, Anim. Behav. 52 (1996) 1079-1085.

[18] Y. Matsumoto, R. Menzel, J.C. Sandoz, M. Giufa, Revisiting olfactory classical conditioning of the proboscis extension response in honey bees: a step toward standardized procedures, J. Neurosci. Methods 211 (2012) 159-167.

[19] A. Fiala, U. Muller, R. Menzel, Reversible downregulation of protein kinase A during olfactory learning using antisense technique impairs long-term memory formation in the honeybee, Apis mellifera, J. Neurosci. 19 (1999) 10125-10134.

[20] A. Si, P. Helliwell, R. Maleszka, Effects of NMDA receptor antagonists on olfactory learning and memory in the honeybee [Apis mellifera], Pharmacol. Biochem. Behav. 77 (2004) 191-197.

[21] W. Blenau, J. Erber, Behavioural pharmacology of dopamine, serotonin and putative aminergic ligands in the mushroom bodies of the honeybee [Apis mellifera], Behav. Brain Res. 96 (1998) 115-124.

[22] T. Farooqui, K. Robinson, H. Vaessin, B.H. Smith, Modulation of early olfactory processing by an octopaminergic reinforcement pathway in the honeybee, J. Neurosci. 23 (2003) 5370-5380.

[23] J.R. Kucharski, J. Maleszka, S. Foret, R. Maleszka, Nutritional control of reproductive status in honeybees via DNA methylation, Science 319 (2008) 1827-1829.

[24] M. Dacher, M. Gauthier, Involvement of NO-synthase and nicotinic receptors in learning in the honey bee, Physiol. Behav. 95 (2008) 200-207.

[25] Y. Matsumoto, J.C. Sandoz, J.M. Jean-Marc Devaud, F. Lormant, M. Mizunami, M. Giurfa, Cyclic nucleotide-gated channels, calmodulin, adenylyl cyclase, and calci$\mathrm{um} /$ calmodulin-dependent protein kinase II are required for late, but not early, long-term memory formation in the honeybee, Learn. Mem. 21 (2014) 272-286.

[26] Y.L. Wang, M.L. Yang, F. Jiang, J.Z. Zhang, L. Kang, MicroRNA-dependent development revealed by RNA interference-mediated gene silencing of LmDicer1 in the migratory locust, Insect Sci. 20 (2013) 53-60.

[27] A.S. Cristino, A.R. Barchuk, F.C.P. Freitas, R.K. Narayanan, S.D. Biergans, Z. Zhao, Z.L. Simões, J. Reinhart, C. Claudianos, Neuroligin-associated microRNA-932 targets actinand regulates memory in the honeybee, Nat. Commun. 5 (2014) 5529.

[28] Q.H. Qin, Z.L. Wang, L.Q. Tian, H.Y. Hai-Yan Gan, S.W. Zhang, Z.J. Zeng, The integrative analysis of microRNA and mRNA expression in Apis mellifera following mazebased visual pattern learning, Insect Sci. 21 (2014) 619-636.

[29] R. Hadar, R. Menzel, Memory formation in reversal learning of the honeybee, Front. Behav. Neurosci. 13 (4) (2010) 186

[30] H. Hahne, F. Pachl, B. Ruprecht, S.K. Maier, S. Klaeger, D. Helm, G. Médard, M. Wilm, S. Lemmer, B. Kuster, DMSO enhances electrospray response, boosting sensitivity of proteomic experiments, Nat. Methods 10 (2013) 989-991.

[31] Carvalho PC, Fischer JSG, Xu T, Yates JR III, Barbosa VC. PatternLab: from mass spectra to label-free differential shotgun proteomics, Curr Protoc Bioinforma, Ed. Board Andreas Baxevanis Al. Chapter 13 (2012) Unit13.19.

[32] J.K. Eng, T.A. Jahan, M.R. Hoopmann, Comet: an open-source MS/MS sequence database search tool, Proteomics 13 (2013) 22-24.

[33] P.C. Carvalho, J.S.G. Fischer, T. Xu, D. Cociorva, T.S. Balbuena, R.H. Valente, J. Perales, J.R. Yates III, V.C. Barbosa, Search engine processor: filtering and organizing peptide spectrum matches, Proteomics 12 (2012) 944-949.

[34] B. Zhang, M.C. Chambers, D.L. Tabb, Proteomic parsimony through bipartite graph analysis improves accuracy and transparency, J. Proteome Res. 6 (2007) 3549-3557.

[35] B. Zybailov, A.L. Mosley, M.E. Sardiu, M.K. Coleman, L. Florens, M.P. Washburn, Statistical analysis of membrane proteome expression changes in Saccharomyces cerevisiae, J. Proteome Res. 5 (2006) 2339-2347.

[36] S. Götz, R. Arnold, P. Sebastián-León, S. Martín-Rodríguez, P. Tischler, M.A. Jehl, J. Dopazo, T. Thomas Rattei, A. Conesa, B2G-FAR, a species-centered GO annotation repositor, Bioinformatics 27 (2011) 919-924. 
[37] The Gene Ontology Consortium, Gene ontology consortium: going forward, Nucleic Acids Res. 43 (2015) (D1049-1010 56).

[38] Q. Zheng, X.J. Wang, GOEAST: a web-based software toolkit for gene ontology enrichment analysis, Nucleic Acids Res. 36 (2008) W358-W363.

[39] Y. Benjamini, D. Yekutieli, The control of the false discovery rate in multiple testing under dependency, Ann. Stat. 29 (2001) 1165-1188.

[40] A. Franceschini, D. Szklarczyk, S. Frankild, M. Kuhn, M. Simonovic, A. Roth, J. Lin, P. Minguez, P. Bork, C. von Mering, L.J. Jensen, STRING v9.1: protein-protein interaction networks with increased coverage and integration, Nucleic Acids Res. 41 (2013) D808-D815.

[41] L. Garcia, C.H.S. Garcia, L.K. Calábria, G.C. Nunes da Cruz, A.S. Puentes, S.N. Báo, W. Fontes, C.A.O. Ricart, F.S. Espindola, M.V. Sousa, Proteomic analysis of honey bee brain upon ontogenetic and behavioral development, J. Proteome Res. 8 (2009) 1464-1473.

[42] B. Baer, A.H. Millar, Proteomics in evolutionary ecology, J. Proteome (2015), http:// dx.doi.org/10.1016/j.jprot.2015.09.031.

[43] M. Heisenberg, What do the mushroom bodies do for the insect brain? An introduction, Learn. Mem. 5 (1998) 1-10.

[44] S.A. Fahrbach, J.L. Strande, G.E. Robinson, Neurogenesis is absent in the brains of adult honey bees and does not explain behavioral neuroplasticity, Neurosci. Lett. 197 (1995) 145-148.

[45] A. Zayed, G.E. Robinson, Understanding the relationship between brain gene expression and social behavior: Lessons from the honey bee, Annu. Rev. Genet. 46 (2012) 591-615. 